\title{
Explotación ilícita de yacimientos mineros y su relación con la pobreza en Chocó, Colombia. Estado actual y desafíos para el Ejército Nacional ${ }^{1}$
}

\author{
César Augusto Mejía Leyton ${ }^{2}$ \\ Escuela Superior de Guerra "General Rafael Reyes Prieto" \\ Leidy Johana Cabrera Cabrera ${ }^{3}$ \\ Escuela de Aviación del Ejército \\ John Cristhian Fernández Lizarazo ${ }^{4}$ \\ Universidad de La Salle
}

\section{Resumen}

El fenómeno de la explotación ilícita de yacimientos mineros en el Departamento del Chocó tiene un efecto directo sobre la pobreza, lo que representa un reto para el país que debe ser manejado desde diferentes sectores sociales, políticos y económicos. El Ejército Nacional de Colombia, como parte de su misión constitucional ha hecho frente a la problemática generando diferentes estrategias para este territorio. En este sentido, este capítulo analiza el papel del Ejército Nacional en las condiciones sociales asociadas a la pobreza que determinan

1 Este capítulo incluye los resultados de la monografía de grado titulada "Condiciones sociales asociadas a la pobreza que determinan la minería ilegal en Chocó, Colombia: el papel del Ejército Nacional" y del proyecto de investigación "Acciones estratégicas del Ejército Nacional orientadas al desarrollo sostenible", del grupo de investigación en Aviación Militar de la Escuela de Aviación del Ejército, registrado con el código COL0077618 y categorizado en C por Minciencias. Los puntos de vista pertenecen a los autores y no reflejan necesariamente los de las instituciones participantes.

2 Teniente coronel del Ejército Nacional de Colombia. Magíster en Estrategia y Geopolítica y especialista en Seguridad y Defensa Nacionales de la Escuela Superior de Guerra "General Rafael Reyes Prieto". Especialista en Administración de Recursos para la Defensa de la Escuela de Armas Combinadas del Ejército. Profesional en Ciencias Militares de la Escuela Militar de Cadetes "General José María Córdova”, Bogotá, D. C., Colombia. Contacto: cesar.mejia@buzonejercito.mil.co

3 Magíster y especialista en Docencia e Investigación Universitaria de la Universidad Sergio Arboleda. Trabajadora social de la Universidad de La Salle. Investigadora del grupo de investigación en Aviación Militar de la Escuela de Aviación del Ejército. ORCID: https://orcid.org/0000-0002-6398-6933. Contacto: leidycabreracabrera@cedoc.edu.co

4 Doctor y magíster en Ciencias Agrarias de la Universidad Nacional de Colombia. Licenciado en Biología de la Universidad Distrital Francisco José de Caldas. Director del programa de Ingeniería Agronómica de la Universidad de La Salle. ORCID: https://orcid.org/0000-0001-9015-7404. Contacto: johfernandez@lasalle.edu.co 
la minería ilegal en el Departamento del Chocó, Colombia. Se trata de un estudio cualitativo de tipo descriptivo. Los resultados indican que las estrategias integrales pueden fortalecer el impacto que tienen las acciones del Ejército Nacional, lo que a su vez contribuye a la construcción de planes, programas y proyectos encaminados a mejorar las condiciones de vida de los habitantes del Departamento del Chocó que se han visto afectados por este fenómeno.

Palabras clave: Chocó; condiciones sociales; desarrollo social; Ejército Nacional de Colombia; minería ilegal.

\section{Introducción}

Colombia posee una abundancia de recursos naturales que debería ser la base de su distribución productiva y de su especialización para el comercio internacional. Sin embargo, las economías ilegales han dejado daños importantes que afectan el desarrollo del país. La explotación ilícita de yacimientos mineros o minería ilegal corresponde a parte de estas economías, que cada vez van tomando mayor fuerza.

La minería en Colombia está considerada como una de las actividades económicas con mayor crecimiento y desarrollo en los últimos años (Serrano, Martínez $\&$ Fonseca, 2015). Sin embargo, su falta de formalización genera estructuras inadecuadas que impiden el avance de los territorios y llevan al aumento de los niveles de pobreza.

El fenómeno de minería ilegal está asociado a la falta de institucionalidad, a la presencia de grupos armados y a fenómenos sociales, especialmente a la pobreza, que impactan de forma importante la calidad de vida de los habitantes del Departamento. Esta actividad ilegal se desarrolla mediante procesos informales por fuera de parámetros legales, ambientales, técnicos y laborales (Fedesarrollo, 2008; Neil et al., 2011) y constituye más del $90 \%$ de las unidades productivas destinadas a la minería (Censo Minero de 2012), razón por la cual es importante analizarla a partir de los tres fenómenos previamente mencionados.

En el caso de los dos primeros factores descritos, es claro que la ausencia histórica de instituciones capaces de regular la actividad minera, la llegada de grupos armados ilegales y su implicación en dicha actividad constituye hoy una situación especialmente grave en términos humanitarios (Defensoría del Pueblo, 2017). Frente a estas situaciones, el papel del Ejército Nacional en el Departamento del Chocó ha estado orientado a combatir los grupos armados ilegales y reestablecer la institucionalidad a través del desarrollo de operaciones militares conjuntas entre 
la Unidad contra la Minería Ilegal en la Policía Nacional (UNIMIN) y la Brigada contra la Minería Ilegal en el Ejército Nacional (BRCMI). La primera de estas entidades destruye la maquinaria incautada, la segunda ejerce control territorial. Además, se realizan operaciones conjuntas y coordinadas entre el Ejército Nacional, la Policía, la Armada, la Fuerza Aérea, la Fiscalía, el CTI, el Ministerio de Minas y las autoridades ambientales ("La lucha contra la minería ilegal...", 2018; Tovar \& Figueroa, 2020).

En contraste, el abordaje de los fenómenos sociales asociados a la minería ilegal es aún más complejo. El indicador de Necesidades Básicas Insatisfechas (NBI) del Departamento del Chocó alcanza aproximadamente el 79,19\%, frente al 27,78 \% de la media nacional ("En el Chocó comunidades están confinadas...", 2019); según las estadísticas registradas en el Plan de Desarrollo 2016-2019, Chocó posee una población en pobreza extrema de 39,1\%, cuando la del país es de 8,1\% (Gobernación del Chocó, 2017).

Estas condiciones acentúan la histórica presencia de grupos armados ilegales ubicados en el territorio, los cuales participan de forma directa buscando apropiarse de las ganancias generadas en procesos de administración de operaciones mineras y/o comercialización (Rettberg \& Ortiz, 2014). Además, la dificultad para que lleguen las instituciones y los beneficios del Estado aumentan la situación de pobreza de esta población, lo que la hace dependiente, en gran medida, de las actividades ilícitas y favorece el conflicto al sustentar las condiciones de disputa entre distintos actores (Defensoría del Pueblo, 2017). En este sentido, el departamento enfrenta condiciones socioeconómicas precarias en diferentes niveles, que atentan contra la biodiversidad y la calidad de vida de los pobladores, de manera que ponen en riesgo permanente la garantía de los Derechos Humanos.

Desde esta perspectiva, aunque es claro que la minería ilegal es un problema que puede estar asociado a las condiciones sociales particulares en Chocó (Colombia), como la pobreza, no se conoce a fondo la forma en la que esta interactúa para determinar el fenómeno en mención. Las razones de esto son varias: (1) es un fenómeno dinámico y cambiante por cuanto está sujeto a una dinámica nacional de incertidumbre. (2) La información existente es muy variada y de diferente naturaleza, lo cual insta a recoger y ponderar dicha información para que sea de utilidad en el análisis del fenómeno. (3) Los actores que participan en este fenómeno son diversos $y$, en ocasiones, radicalmente opuestos, de tal forma que la visión individual puede sesgar el fenómeno como tal.

La importancia de la minería en Colombia es que, si se administra adecuadamente, ofrece la oportunidad de promover un desarrollo de base amplia y reducir 
la pobreza (Serrano, Martínez \& Fonseca, 2016). El Ejército Nacional, a través de su labor, impacta en las condiciones sociales del departamento, especialmente la pobreza, lo que puede contribuir a la definición de nuevas líneas de trabajo. Sin embargo, y a pesar de su importancia estratégica, la falta de claridad de la relación que existe entre los fenómenos sociales particulares del Departamento del Chocó y la minería ilegal no permite comprender la forma como el Ejército Nacional podría tener impacto sobre los fenómenos sociales que determinan la minería ilegal.

En este sentido, la minería ilegal configura una problemática social vigente que afecta el desarrollo del país y por ende la calidad de vida de las poblaciones en las que se produce. La expresión más clara de este fenómeno es el incremento de la pobreza en el territorio. En este sentido, hacer frente a esta problemática impacta directa o indirectamente la disminución de la pobreza.

Esto coincide con la Decisión 1994/308 del Consejo Económico y Social de la Organización de las Naciones Unidas (ONU, 1994), la cual establece que "cuando un gobierno toma medidas para crear un entorno más propicio para los mineros artesanales, está aumentando también el acceso de la población a una red de seguridad de los ingresos y generando capacidad para liberarse de la pobreza", lo que debe promover la adopción de medidas legales para regularizar este tipo de explotación (Defensoría del Pueblo, 2017).

De este modo, a través de sus diferentes instituciones, el Estado está llamado a manejar adecuadamente el fenómeno de la minería ilegal en departamentos como el Chocó por todos los efectos negativos que genera.

El Ejército Nacional no es ajeno a estas preocupaciones, pues se le han encomendado tareas relacionadas con la lucha contra la explotación ilícita de yacimientos mineros, a través de estrategias militares y de tipo social, que se consolidan en la medida en que se identifican nuevas estructuras de intervención. Respecto a las estrategias sociales, se trata de un proceso que apenas se está consolidando en el Departamento del Chocó a través de acciones como proyectos productivos y relaciones interinstitucionales, por lo cual se convierte en un punto de análisis de gran interés para la institución militar y para el mismo departamento.

En este sentido, se realizó un estudio de tipo cualitativo que permitió identificar las principales condiciones sociales asociadas a la pobreza que inciden en la minería ilegal en Chocó (Colombia), identificar las estrategias que ha desarrollado el Ejército Nacional respecto a la minería ilegal en el departamento y determinar la relación entre las acciones que realiza el Ejército Nacional contra la minería ilegal y su efecto potencial sobre las condiciones sociales asociadas a la pobreza en esa región. 
Desde la estructura propuesta se presentan retos para el Ejército Nacional en términos de la proyección y comprensión de su papel para hacer frente al fenómeno de la minería ilegal con acciones que incidan en ámbitos sociales importantes del territorio chocoano.

\section{Métodos}

Se realizó una investigación de carácter cualitativo que incluyó dos técnicas: la primera fue la revisión documental, mediante el análisis de diferentes referentes, fuentes primarias de las principales bases de datos de investigaciones relacionadas con el objeto de estudio, así como revisión de prensa, para lo cual se utilizó como instrumento los Resúmenes Analíticos Explicativos (RAES). Por su parte, la segunda técnica fue la entrevista en profundidad dirigida a miembros del Ejército Nacional que coordinan procesos militares frente a la minería ilegal en el Departamento del Chocó.

El proceso de investigación se desarrolló en tres fases. En un primer momento se presentan las principales condiciones sociales asociadas a la pobreza que inciden en la minería ilegal en el Departamento del Chocó. En un segundo grupo se presentan las principales estrategias que ha desarrollado el Ejército Nacional contra la minería ilegal en la región y se definen los avances y retos de las acciones operacionales, estratégicas y de tipo social. Estas últimas representan un especial interés pues están asociadas directamente con fenómenos de pobreza en el departamento.

Este proceso constituyó el eje central de la investigación, pues incluyó las percepciones de los oficiales que trabajan en esta área de acción, así como de los representantes institucionales y líderes comunitarios que representan la voz de los trabajadores. Las técnicas y los instrumentos que se utilizaron están enfocados en el análisis documental y las entrevistas en profundidad, que fueron procesadas en el software de análisis de datos cualitativos Atlas Ti 7.0.

Finalmente, en la tercera fase se muestra las acciones del Ejército Nacional contra la minería ilegal y su efecto potencial sobre las condiciones sociales asociadas a la pobreza del Departamento del Chocó. Este trabajo representa un primer acercamiento al proceso de transformación en el que avanza actualmente el Ejército Nacional, pues busca poner en evidencia el trabajo que está haciendo, pero también mostrar los vacíos que se podrían fortalecer para mejorar las condiciones del territorio chocoano. 


\section{Condiciones sociales asociadas a la pobreza que inciden en la minería ilegal}

Según el contexto y la necesidad, se han desarrollado diferentes enfoques para entender la pobreza. Una de las definiciones con mayor fuerza sostiene que es la carencia de capacidades y derechos que, junto con otros elementos de "desigualdad", impiden a la población potenciar sus capacidades (Corredor, 1999). Sin embargo, y dada la amplitud del concepto, este estudio analiza la pobreza no solo desde la carencia de recursos y capacidades, sino que también considera necesario abordarla desde una perspectiva relacional.

Así pues, la pobreza también se puede ver como un conjunto de relaciones sociales en las cuales las personas están excluidas de participar de una vida social normal, es decir, la exclusión resultante de la limitación de los recursos: "Se considerarán pobres aquellas personas, familias y grupos de personas cuyos recursos (materiales, culturales y sociales) son limitados a tal punto que quedan excluidos del estilo de vida mínimamente aceptable para el Estado Miembro en el que habitan” (EEC, 1985).

En todo caso, el concepto de pobreza es multidimensional, es decir, está vinculado a múltiples dimensiones del ser humano y de la sociedad (Eurosur, s. f.). En este sentido, el análisis de la pobreza asocia dos nociones a este concepto: la primera noción es la de pobreza como carencia o necesidades insatisfechas, mientras que la segunda es la de pobreza como falta de desarrollo de las capacidades (Gallego, 2009).

Para Gallego (2009), la medición de necesidades insatisfechas es esencialmente unidimensional y restringida al aspecto monetario, mientras que la pobreza de capacidades reconoce que las personas poseen una serie de atributos, cuantitativos y cualitativos, que abarcan, además de la dimensión monetaria, dimensiones del ser, de manera que se puede originar por múltiples causas y sus efectos pueden ser variados.

Así, Gallego (2009) afirma que es posible estudiar la pobreza mediante mecanismos causales, que si bien se alejan de la obtención de índices comparativos, sí permiten acercarse con mayor claridad a la comprensión del problema social, dado que la pobreza puede responder a patrones o tendencias, incluso a mecanismos persistentes en el tiempo. De esta forma, los resultados obtenidos mediante estos análisis permiten hacer propuestas paliativas de este problema social específico y localizado.

La literatura académica ha planteado cuatro mecanismos causales de la pobreza, que fueron descritos inicialmente por Wright (1995; citado por Gallego, 
2009). Dos de ellos toman al individuo o a la sociedad como la unidad de análisis y explican que la pobreza puede ser el resultado de dos factores: (1) las características genéticas y raciales asociadas con falta de inteligencia, lo que pone al individuo y a su comunidad en desventaja con otras, y (2) el conjunto de hábitos y valores individuales y sociales que se transmiten a través del tiempo y que tienen impacto directo en el aumento de la pobreza. Los otros dos mecanismos sugieren el análisis a partir de características inherentes al sistema, de forma que la pobreza se considera el resultado de (3) la falta de oportunidades educativas, de empleo y de malas políticas gubernamentales que dan como resultado la disminución de oportunidades, y finalmente, (4) la estructura económica capitalista, que explicaría de manera indirecta actores asociados con la explotación y el consecuente aumento de la pobreza (figura 1).

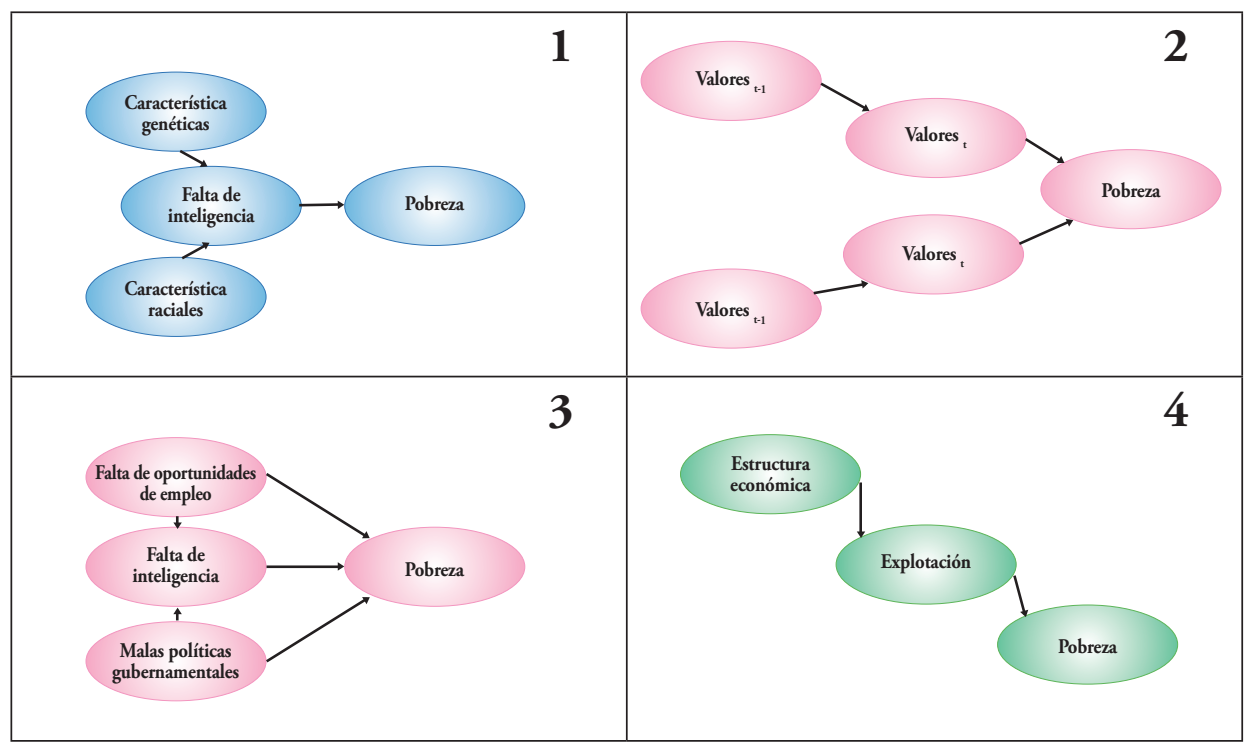

Figura 1. Componente estructural de los mecanismos sociológicos explicativos de la pobreza. Fuente: Adaptado de Gallego (2009) y Wright (1995).

A partir de lo anterior y ante la complejidad que sugiere el análisis de los cuatro mecanismos causales de la pobreza, en este trabajo se eligió el mecanismo que se ajustara mejor a la información disponible acerca de la pobreza y los factores sociales asociados a ella en el Chocó. De esta forma, se seleccionó el tercer mecanismo causal de la pobreza como punto de partida para desarrollar los análisis posteriores. A continuación, se amplía el significado de cada uno de los componentes de este mecanismo causal de pobreza en el contexto del Departamento del Chocó. 


\section{La falta de oportunidades educativas}

El $20 \%$ de los chocoanos no ha tenido la oportunidad de educarse al menos a nivel de formación básica. Si bien es cierto que el departamento cuenta con una red conformada por 207 instituciones educativas oficiales y 1.214 sedes, en donde se forman más de 142 mil nińos y jóvenes, su administración ha sido cuestionada. Por ejemplo, en el año 2009, el Ministerio de Educación Nacional (MEN) tuvo que intervenir a la Secretaría de Educación Departamental del Chocó por un periodo de más de ocho años.

Con respecto a la educación de calidad, en el Departamento del Chocó es extremadamente baja en relación con los estándares internacionales e incluso con los nacionales. Según datos recopilados en el Plan Estratégico de Mejoramiento de la Calidad Educativa en el Departamento del Chocó, el nivel de desempeño en las pruebas de Estado se encuentra muy por debajo del promedio de Colombia, que lo han ubicado recientemente en los últimos lugares en rendimiento académico del país. Por ejemplo, el porcentaje promedio de estudiantes en los niveles más bajos de rendimiento (mínimo e insuficiente) en las pruebas de lenguaje y matemáticas (79 \% y $81 \%$, respectivamente), es significativamente mayor al del promedio nacional ( $57 \%$ y $64 \%$, respectivamente).

Los factores clave que influyen en los resultados de la calidad de la educación se pueden resumir de la siguiente manera: (1) servicio público educativo débil, sujeto a amenazas por corrupción, ilegalidad y recibe influencias de sectores políticos e incluso de grupos armados; (2) implementación inadecuada de políticas de mejoramiento de la calidad de las instituciones educativas por parte del MEN, por cuanto existen serias dificultades en la gestión y la administración; (3) falta de calidad en la formación docente y prácticas en el aula porque los docentes inician en sus procesos de formación como educadores, principalmente en las instituciones educativas normales y en las universidades del departamento, que aún no cuentan con estándares altos de calidad; (4) un contexto local prometedor, pero poco motivante, que genera pocos incentivos a la calidad educativa en docentes y estudiantes, como la inadecuada remuneración de los maestros y un entorno social en el que los estudiantes y sus familias se ven inmersos como víctimas del conflicto armado y de los cultivos ilícitos; (5) la alta deserción escolar, la cual ha tenido preocupantes tendencias al aumento, pues ha pasado de 1.158 a 4.093 estudiantes entre 2013 y 2015. En contraste, los estudiantes, principalmente en el sector rural y en las zonas periurbanas del departamento, encuentran su sustento en la renta que producen actividades económicas como la minería aluvial, la extracción forestal, 
los cultivos ilícitos y la participación en grupos armados y bandas delincuenciales (Gobernación del Chocó, 2017).

\section{La falta de oportunidades de empleo}

Para comprender este componente como parte fundamental en el mecanismo causal de la pobreza en el Chocó, es necesario describir no solamente el empleo (o desempleo) del departamento, sino también su contexto económico. Por lo tanto, a continuación se describe una serie de índices útiles en la comprensión del fenómeno.

Con el 18,6 \%, el Departamento del Chocó se ubicó, según el DANE (2019), en el primer lugar de desempleo del país en julio de 2019, puesto que ha mantenido durante los últimos cuatro años. Según la Cámara de Comercio del Chocó, esto se debe a la insipiencia en el sector empresarial.

El Producto Interno Bruto (PIB) es un indicador apropiado para entender la dinámica económica del Chocó. La participación del Departamento del Chocó en el PIB nacional es apenas del 0,39\%, con un PIB per cápita de US\$2.601 frente a un PIB per cápita nacional de US\$6.922. Además, la discriminación del PIB por sectores económicos permite distinguir que en todos es muy inferior, con excepción de (1) Minas y canteras, (2) Agricultura, ganadería y pesca, y (3) Administración pública y defensa.

Otro índice que permite comprender la situación económica del Departamento del Chocó es el Índice Departamental de Competitividad (IDC), que, según el Consejo Privado de Competitividad (CPC) y el Centro de Pensamiento en Estrategias Competitivas de la Universidad del Rosario (CEPEC), tiene el objetivo de medir diferentes aspectos que inciden sobre el nivel de competitividad de los departamentos en Colombia. El IDC mide diez parámetros agrupados en tres factores, como se muestra en la figura 2.

Con el propósito de permitir una comparación por niveles de desarrollo similares, el Departamento del Chocó se ubica en el mismo grupo de Caquetá, Córdoba, Nariño y Sucre, todos caracterizados por un bajo desarrollo económico. De hecho, el Departamento del Chocó se ha ubicado en el último lugar entre todos los departamentos de Colombia durante los últimos seis años, con un IDC de entre 2,5 y 2,7, frente a valores de 6,78 y 8,24 de Antioquia y Bogotá, respectivamente (Consejo Privado de Competitividad, 2018).

En términos concretos, el Departamento del Chocó tiene una participación del $0,1 \%$ del total de las exportaciones de Colombia. De forma interesante, el oro representó el 91,6\% de las exportaciones chocoanas. Por su parte, las impor- 


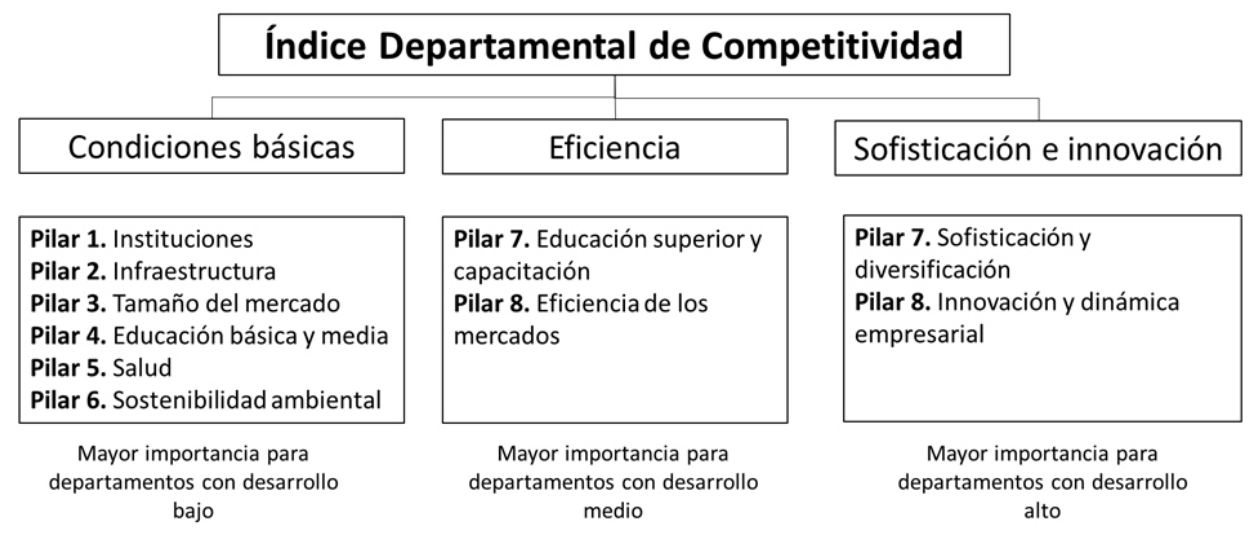

Figura 2. Factores de competitividad.

Fuente: Consejo Privado de Competitividad (2018).

taciones de Chocó tuvieron una participación promedio menor al 0,1\% de las importaciones nacionales entre 2011 y 2018. Para este último ańo, los bienes de capital y materiales de construcción representaron el 71,4 \% de las importaciones del departamento. Particularmente para los años 2016 y 2017, las partes para máquinas fueron los principales productos de importación.

\section{Las malas políticas gubernamentales}

Según la Defensoría del Pueblo (2019), las políticas públicas son prácticamente inexistentes en Chocó, lo que supone que es necesario realizar un esfuerzo para superar esta condición y, en consecuencia, invertir de acuerdo con lo que realmente necesita la población. En este sentido, es notoria y grave la ausencia de políticas públicas orientadas a mejorar la calidad de vida de la población, a disminuir las afectaciones al ambiente debido a los proyectos de carácter extractivo y a contrarrestar las constantes violaciones de Derechos Humanos hacia las comunidades.

Existen numerosos ejemplos del fracaso de políticas públicas en el Chocó. A continuación, se detallan algunos de ellos, particularmente en el deporte, la educación y la equidad de género. Con respecto al deporte, debido a su debilidad, recientemente se ha propuesto que las políticas de este sector sean reformuladas. Según la misma fuente, los mayores problemas en cuanto a políticas públicas están asociados a las fuentes financieras, la normatividad, la administración de recursos, la infraestructura deportiva, las organizaciones territoriales, la capacitación, la educación y la formación, la inclusión y la cobertura, la comunicación y la articulación, la institucionalidad, la politización y la formulación e implementación de la política. 
En el sector de la educación, las políticas públicas de cobertura, particularmente para la educación superior en el Departamento del Chocó, han tenido resultados poco proporcionales con respecto a los avances nacionales, lo cual indica que no han sido suficientes con respecto a la cantidad y a las características de la población. Entre las principales razones de este rezago se encuentran la corrupción, la poca presencia institucional, especialmente en los estratos sociales menos favorecidos, la baja inversión social y la inequidad en la distribución de la riqueza de los servicios y las oportunidades. Estas razones también están vinculadas con otras emergentes, como el conflicto armado y el narcotráfico.

El panorama también es similar en las políticas etnoeducativas, necesarias para la conservación de la identidad y la territorialidad. Estas políticas son insuficientes para atender los problemas que plantea la etnoeducación en el Chocó, en la medida en que no se acercan a la realidad ni a las necesidades de los territorios. Hay falta de planeación, proyección, estructuración e implementación adecuadas, además de que presenta serias dificultades para definir acciones concretas que permitan acercarla a la realidad y necesidades que tienen los territorios.

Otra de las necesidades más apremiantes en el Departamento del Chocó, por cuanto también han sido insuficientes, son las políticas públicas orientadas hacia la equidad de género, especialmente en poblaciones negras victimizadas por el conflicto armado, el narcotráfico y los grupos ilegales. Por esta razón, este tema ha sido recientemente objeto de interés, especialmente en cuanto a construcción y diseño de políticas públicas e intentos aún necesarios de reconstruir la familia en las comunidades afectadas.

Frente al fracaso de las políticas públicas en varios sectores en el departamento, es necesario advertir que el desarrollo social y las relaciones de producción del Chocó son diferentes a las del resto del país y que por este motivo las políticas públicas para el Chocó deben ser diferentes en razón de que el desarrollo de la capacidad productiva y las relaciones sociales en el departamento así lo ameritan.

Otra de las razones que han tenido mayor peso en el fracaso de las políticas públicas en el Departamento del Chocó ha sido la corrupción. En las últimas décadas se puede apreciar el descalabro social al que se ha visto abocado el Departamento del Chocó debido a la corrupción del sector público. Según datos del Índice de Transparencia Departamental para Contralorías, vigencia 20132014 (Transparencia por Colombia, 2014), el Chocó obtuvo una calificación de 29,5, frente al promedio nacional de 59,1, de manera que se ubica como la segunda más baja después del Amazonas, además de que tiene un nivel de riesgo considerado como muy alto. Dentro del mismo informe, los factores de políticas 
y medidas anticorrupción, políticas de comportamiento ético y organizacional, Control Institucional y Control Interno de Gestión obtuvieron una calificación de cero $(0,0)$.

La falta de oportunidades educativas y de empleo, así como las malas políticas gubernamentales — componentes del tercer mecanismo sociológico que explica la pobreza - son determinantes causales de la pobreza en el Chocó y son medidos de forma permanente y principalmente a partir de indicadores monetarios.

De acuerdo con el Boletín Técnico sobre Pobreza Monetaria Departamental, realizado por el DANE (2018), el Departamento del Chocó obtuvo en el año 2018 uno de los porcentajes más altos en diferentes niveles: fue el departamento con mayor brecha de la pobreza monetaria, mayor aumento en la incidencia de la pobreza monetaria y menor crecimiento nominal de la línea de pobreza monetaria (DANE, 2018).

Investigadores del Banco de la República han aportado evidencia de que gran parte del Pacífico colombiano se encuentra en condiciones de pobreza importantes, lo cual no le ha permitido superar los bajos niveles de ingreso ni las altas tasas de analfabetismo (Galvis, Moyano \& Alba, 2016); los mismos autores plantean que las actividades económicas basadas en la ilegalidad sobredimensionan el problema de la pobreza. No obstante, el análisis documental realizado también permite evidenciar que este mecanismo causal de la pobreza no explica suficientemente el fenómeno descrito con respecto a la pobreza en el Chocó.

En este contexto de pobreza en el que se encuentra sumergido el departamento, ha surgido otro factor que en la actualidad se debe tratar no solo como una consecuencia, sino también como un determinante de la pobreza. Este factor es el conflicto armado y la violencia por la que atraviesa en general la región Pacífica.

Hace años, Chocó fue declarado remanso de paz, pero esto ha cambiado con el tiempo. Ahora, en el departamento y su capital, Quibdó, están todos los grupos armados, tanto ilegales como legales. Actualmente, se han registrado en Chocó un gran número de hechos de violencia, como saqueos, enclaves, tomas, desalojos, desarraigos y desplazamientos o confinamientos forzados, al igual que masacres.

Hasta 2019, en el Departamento del Chocó se han declarado 285.189 víctimas. A finales del siglo pasado y a principio de este, así como entre el periodo comprendido entre 2011 y 2017 la tasa de personas desplazadas por expulsión estuvo por encima de las doce mil al año.

Para el año 2015, la tasa de homicidio en Chocó por cada cien mil habitantes fue de 28,99. No obstante, en el departamento se encuentra uno de los municipios 
con la tasa más alta del país, se trata de San José del Palmar, con 186,64 homicidios por cada cien mil habitantes. Es importante considerar que esta tasa para Colombia es de 24,03 y que en el periodo 2000-2012 las tasas de homicidio se han reducido en poco más del $16 \%$ en todo el mundo (de 8 a 6,7 por cada cien mil habitantes) (Unidad para la Atención y Reparación Integral de las Víctimas, 2019).

Escobedo y Guío (2015) realizaron una investigación alrededor del crimen organizado, las guerrillas y el oro en Quibdó. Estos autores encontraron un aumento significativo de los homicidios en 2012 y 2013, que está directamente relacionado con el auge del oro, principalmente. Otro hallazgo fue que las disputas entre grupos armados ilegales (i.e. Los Rastrojos y Los Urabeños) estuvieron vinculadas a la disputa en torno a las rentas del oro. Finalmente, la investigación también estableció que mientras las guerrillas y especialmente las FARC extraían excedentes del oro en el sector rural (minas, entables y ríos), las bandas criminales hacían lo propio en el urbano usando la ciudad como centro de compra de oro para financiar la explotación de este metal, el lavado del narcotráfico y la corrupción que permite la explotación sin licencia (Escobedo \& Guío, 2015).

Uno de los grupos más afectados ha sido la población indígena. Más de dos mil indígenas en el norte del Chocó han sido desplazados debido a los enfrentamientos entre el Ejército de Liberación Nacional (ELN) y las Autodefensas Gaitanistas de Colombia (AGC). Los enfrentamientos entre grupos armados en los municipios de Riosucio, Carmen del Darién y Bojayá han victimizado a más de catorce comunidades indígenas (751 familias), que actualmente están confinadas en el Chocó ("En el Chocó comunidades están confinadas...”, 2018).

La riqueza minera y biológica de la región no ha sido un activo democratizador, sino una fuente de enclaves económicos y rentas capturadas por los grupos armados mediante la violencia, el terror y la barbarie. De hecho, es una de las zonas donde las amenazas han hecho fracasar los procesos productivos y la restitución voluntaria de cultivos ilícitos que forman parte de la implementación del acuerdo de paz.

De esta forma, se propone que la estructura del mecanismo causal de pobreza que se ha tomado como referente en esta investigación se modifique para incluir el conflicto armado y la violencia como un componente adicional, puesto que se evidencia como un agente causante de pobreza en el Departamento del Chocó (figura 3). 


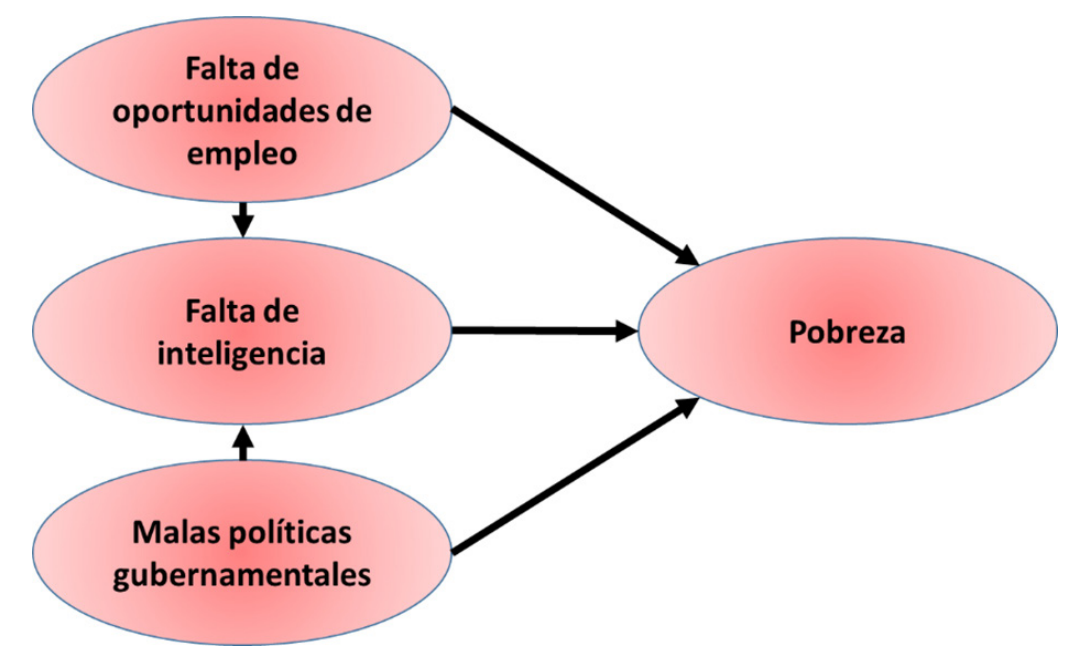

Figura 3. Mecanismo explicativo de la pobreza.

Fuente: Elaborado por los autores.

La revisión de literatura orientada a detectar las condiciones sociales que determinan la minería ilegal permitió definir once condiciones sociales. Es decir, a partir de las investigaciones que analizaban la minería ilegal se identificaron condiciones sociales asociadas potencialmente a la pobreza. Posteriormente estas condiciones sociales que determinan la minería ilegal se vincularon a los componentes del mecanismo explicativo de la pobreza presentado en la figura 3. Estas once condiciones sociales asociadas fueron:

1. Falta de redes de protección social.

2. Competencia en el uso de la biodiversidad.

3. Desigualdad.

4. Violación a los Derechos Humanos.

5. Violación de los derechos laborales.

6. Desplazamiento forzado.

7. Competencia en el uso de la tierra.

8. Corrupción en las instituciones.

9. Disfunción de la gobernanza.

10. Falta de desarrollo sostenible.

11. Falta de servicios sanitarios de calidad.

Estas condiciones sociales se pueden relacionar con cada uno de los componentes del mecanismo explicativo de la pobreza, de forma que se configura un 
sistema complejo de múltiples interacciones. Con el propósito de facilitar el análisis y la comprensión de las condiciones sociales asociadas a la pobreza y la minería ilegal, a continuación, en la tabla 1 se representa la relación de causa/consecuencia entre ellos.

Tabla 1. Componentes del mecanismo explicativo de la pobreza

\begin{tabular}{|c|c|c|c|c|}
\hline \multirow[b]{2}{*}{$\begin{array}{c}\text { Condiciones sociales } \\
\text { asociadas a la pobreza } \\
\text { que inciden en la minería } \\
\text { ilegal }\end{array}$} & \multicolumn{4}{|c|}{$\begin{array}{c}\text { Componentes del mecanismo explicativo } \\
\text { de pobreza en Chocó }\end{array}$} \\
\hline & $\begin{array}{c}\text { Falta de } \\
\text { oportunidades } \\
\text { educativas }\end{array}$ & $\begin{array}{c}\text { Falta de } \\
\text { oportunidades } \\
\text { de empleo }\end{array}$ & $\begin{array}{l}\text { Malas políticas } \\
\text { gubernamentales }\end{array}$ & $\begin{array}{l}\text { Conflicto } \\
\text { armado y } \\
\text { violencia }\end{array}$ \\
\hline $\begin{array}{l}\text { Falta de redes } \\
\text { de protección social }\end{array}$ & $\mathrm{CCO}^{*}$ & $\mathrm{CCO}$ & $\mathrm{CNCO}^{* *}$ & $\mathrm{CCO}$ \\
\hline $\begin{array}{l}\text { Competencia en el uso } \\
\text { de la biodiversidad }\end{array}$ & $\mathrm{CNCO}$ & $\mathrm{CNCO}$ & $\mathrm{CNCO}$ & $\mathrm{CCO}$ \\
\hline Desigualdad & $\mathrm{CCO}$ & $\mathrm{CCO}$ & $\mathrm{CNCO}$ & $\mathrm{IDV}^{* * *}$ \\
\hline $\begin{array}{l}\text { Violación de los } \\
\text { Derechos Humanos }\end{array}$ & IDV & IDV & IDV & IDV \\
\hline $\begin{array}{l}\text { Violación de los } \\
\text { derechos laborales }\end{array}$ & $\mathrm{CNCO}$ & $\mathrm{CNCO}$ & $\mathrm{CNCO}$ & $\mathrm{CNCO}$ \\
\hline Desplazamiento forzado & $\mathrm{CCO}$ & $\mathrm{CCO}$ & $\mathrm{CNCO}$ & $\mathrm{CNCO}$ \\
\hline $\begin{array}{l}\text { Competencia en el uso } \\
\text { de la tierra }\end{array}$ & $\mathrm{CCO}$ & $\mathrm{CCO}$ & $\mathrm{CNCO}$ & $\mathrm{CCO}$ \\
\hline $\begin{array}{l}\text { Corrupción en las } \\
\text { instituciones }\end{array}$ & $\mathrm{CCO}$ & $\mathrm{CCO}$ & $\mathrm{CNCO}$ & IDV \\
\hline $\begin{array}{l}\text { Disfunción de la } \\
\text { gobernanza }\end{array}$ & $\mathrm{CCO}$ & $\mathrm{CCO}$ & $\mathrm{CNCO}$ & IDV \\
\hline $\begin{array}{l}\text { Falta de desarrollo } \\
\text { sostenible }\end{array}$ & IDV & IDV & $\mathrm{CNCO}$ & IDV \\
\hline $\begin{array}{l}\text { Falta de servicios } \\
\text { sanitarios de calidad }\end{array}$ & $\mathrm{CNCO}$ & $\mathrm{CNCO}$ & $\mathrm{CNCO}$ & $\mathrm{CNCO}$ \\
\hline
\end{tabular}


A continuación, se definen cada uno de los factores que conforman la estructura anterior y se explica la relación que tienen con los componentes del mecanismo explicativo de pobreza.

En primer lugar, la falta de red de seguridad para generar ingresos (redes de protección social) hace referencia al dinero, las transferencias en especie, las pensiones sociales, las obras públicas y los programas de alimentación escolar destinados específicamente a los hogares pobres y vulnerables. Implica la falta de programas que reduzcan la desigualdad y también la brecha de pobreza. Los efectos positivos de las transferencias de protección social se producen tanto en los países de ingreso bajo como en los de ingreso mediano (Defensoría de Colombia, 2017). La falta de redes de protección social se considera como una consecuencia de las malas políticas gubernamentales y como una causa de la falta de oportunidades educativas y de empleo, así como del conflicto armado.

En segundo lugar, la biodiversidad se define como la variabilidad de organismos vivos de cualquier fuente, incluidos, entre otras cosas, los ecosistemas terrestres y marinos y otros sistemas acuáticos, así como los complejos ecológicos de los que forman parte; comprende también la diversidad dentro de cada especie, entre las especies y de los ecosistemas (Castillo \& Cárdenas, 2012; Dorado, 2010). Respecto al conflicto armado (presencia de grupos armados ilegales) en torno a los recursos naturales,

se ha resaltado el rol clave que en este sentido desempeñan las instituciones, la geografía y el tipo de recursos involucrados (Berdal \& Malone, 2000; Le Billon, 2000; Elbadawi \& Sambanis, 2000; Collier \& Hoeffler, 2004 \& 2005; DiJohn, 2006); en conjunto, estos factores, en especial el primero y el tercero, determinan tanto la probabilidad como el modo en que un recurso específico puede ser permeado por el conflicto y los actores legales e ilegales que en él participan. (Rettberg \& Ortiz, 2014)

La competencia en el uso de la biodiversidad se considera como una consecuencia de las malas políticas gubernamentales, de la falta de oportunidades educativas y de empleo, pero como un agente detonante del conflicto armado.

En tercer lugar, la desigualdad es considerada como una herramienta crítica constitutiva tanto para comprender la dinámica de la producción y reproducción de las brechas existentes entre los diferentes grupos sociales, como para impugnar y denunciar las asimetrías de poder ("La lucha contra la minería ilegal...", 2018). La desigualdad se considera como una causa de la falta de oportunidades educativas y de empleo, así como también es consecuencia de las malas políticas gubernamentales. Esta condición social es origen, pero también consecuencia del conflicto armado. 
En cuarto lugar, la violación a los Derechos Humanos es el irrespeto a los atributos de dignidad que tiene una persona, una colectividad o un pueblo, y que deben ser respetados y garantizados por los Estados. Así, se constituye como una vulneración a la suma de derechos individuales y colectivos establecidos en constituciones nacionales y en el derecho internacional (Bermúdez et al., 2020a; Defensoría del Pueblo, s. f.; Sierra et al., 2020a).

La violación de los Derechos Humanos se considera como una consecuencia, pero también como un agente causal de las malas políticas gubernamentales, de la falta de oportunidades educativas y de empleo, así como del conflicto armado (Sierra et al., 2020b).

En quinto lugar, la violación de los derechos laborales es determinada por el irrespeto de los atributos de dignidad vinculados con valores materiales y con las formas de sustento o de ingreso de una persona. El derecho a la propiedad o al trabajo son derechos económicos incluidos entre los derechos laborales (Defensoría del Pueblo, s. f.; Rodríguez et al., 2014).

La violación de los derechos laborales se considera como una consecuencia de las malas políticas gubernamentales, de la falta de oportunidades educativas y de empleo, así como del mismo conflicto armado y de la violencia.

En sexto lugar, el desplazamiento forzado sucede cuando una persona se ha visto forzada a migrar dentro del territorio nacional, abandonando su localidad de residencia o actividades económicas habituales porque su vida, su integridad física, su seguridad o libertad personales han sido vulneradas o se encuentran directamente amenazadas (Ley 1448 de 2011).

El desplazamiento forzado se considera una consecuencia de las malas políticas gubernamentales y del conflicto armado y de la violencia, pero claramente origina la falta de oportunidades educativas y de empleo para la población.

En séptimo lugar, la competencia en el uso de la tierra es una de las principales causas del despojo de la tierra a raíz de la implementación de proyectos económicos. Así, esta competencia puede convertirse en una forma soterrada de presión y despojo de la tierra (Neil et al., 2011). La competencia en el uso de la tierra se considera como una consecuencia de las malas políticas gubernamentales, pero es un detonante importante del conflicto armado y de la violencia, así como también es un agente causal de la falta de oportunidades educativas y de empleo para la población.

En octavo lugar, con respecto a las relaciones políticas (corrupción en las instituciones) se ha descrito previamente que un político corruptible acepta sobornos de 
un minero privado para permitir la subnotificación de la extracción de minerales y la evasión del pago de regalías. No existe una relación inequívoca entre las distorsiones económicas en forma de minería ilegal y el grado de extracción de rentas mediante sobornos. A medida que la agencia de auditoría se vuelve más politizada, no se puede descartar la posibilidad de una mayor minería ilegal (Datt, 2016).

La corrupción en las instituciones se considera como una consecuencia de las malas políticas gubernamentales, pero es la causa de la falta de oportunidades educativas y de empleo para la población. El conflicto armado y de violencia puede ser causado por la corrupción, pero de igual forma origina este tipo de fenómenos.

En noveno lugar, la disfunción de la gobernanza constituye la incapacidad para elaborar y aplicar políticas, gestión financiera débil, empleo de recursos públicos en la búsqueda de intereses privados, aplicación arbitraria de leyes y normas, sistemas de toma de decisiones cerrados o no transparentes, asignación de recursos de manera inconsistente y creciente desconfianza entre las partes interesadas (Broman \& Robèrt, 2017; Edelman, Luca \& Svirsky, 2017; Duff \& Downs, 2019).

La disfunción de la gobernanza también se considera como una consecuencia de las malas políticas gubernamentales, pero es la causa de la falta de oportunidades educativas y de empleo para la población. El conflicto armado y de violencia puede ser causado por esta disfunción, pero de igual forma origina este tipo de fenómenos.

En décimo lugar, la falta de desarrollo sostenible hace referencia a que no se concibe un desarrollo que satisfaga las necesidades del presente sin comprometer la capacidad de las futuras generaciones de satisfacer sus propias necesidades. Implica ineficacia para tomar las decisiones correctas ahora para mejorar la vida de las generaciones futuras (PNUD, 2011). El desarrollo sostenible es un proceso instituido socialmente de cambio adaptativo que necesita innovación y un acercamiento integrado (Ba, 2014; ; Bermúdez et al., 2020b; Duff \& Downs, 2019; Kervankiran et al., 2016; Samuel et al., 2012).

La falta de desarrollo sostenible se considera como una consecuencia de las malas políticas gubernamentales. La falta de oportunidades educativas y de empleo, así como el conflicto armado y la violencia no solo son consecuencia de la falta de desarrollo sostenible, sino que, en un proceso que es cíclico en el tiempo, también pueden generan este fenómeno.

Finalmente, la falta de servicios sanitarios de calidad hace referencia a un sistema sanitario ineficiente. Un sistema sanitario se encuentra compuesto por todas aquellas organizaciones que se ocupan de prestar servicios de tipo sanitario, entre ellos, hospitales, profesionales especializados en la salud —como médicos, enfermeras, 
entre otros-, funcionarios, centros de atención de salud y los servicios de salud pública, así como también por otros actores, como redes, sectores, ministerios, instituciones especializadas y organizaciones, que ostentan una concreta y específica función e influencia en el área de la salud de una nación (Egmann et al., 2018).

Se ha demostrado que la desigualdad social en el ámbito de la salud, independientemente de factores como la edad o el sexo, se refleja en mayores indicadores de salud en los estratos altos, en tanto que en los bajos la atención es de menor calidad. Este tipo de inequidad también sucede entre personas que viven en regiones geográficas con mayores índices de pobreza (Mackenbach et al., 2019). La falta de servicios sanitarios de calidad se considera como una consecuencia de las malas políticas gubernamentales, de la falta de oportunidades educativas y de empleo, así como del conflicto armado y la violencia.

El Pacífico colombiano se ha desarrollado de manera desigual, en comparación con otras regiones de Colombia. Esto ha producido que actividades como la minería ilegal, el conflicto y la criminalidad han dificultado el acceso de la población a la educación y, consecuentemente, han limitado el ingreso per cápita, lo que en últimas se ha traducido en pobreza y desigualdad.

Estas condiciones sociales derivadas muestran un panorama desalentador. Sin embargo, son las instituciones públicas y privadas las llamadas a generar estrategias y acciones que permitan disminuir las brechas de la pobreza en el Pacífico y garantizar el acceso a las oportunidades. En este orden de ideas, el Ejército Nacional está avanzando mediante acciones propias de la institución que inciden directa o indirectamente en los factores sociales asociados con la pobreza. Estas acciones se analizan en los siguientes apartados de acuerdo con las categorías antes descritas.

\section{Estrategias que ha desarrollado el Ejército Nacional para combatir la minería ilegal en el Departamento del Chocó}

A continuación se abordan las estrategias militares que desarrolla el Ejército Nacional. Primero se analizan los datos cuantitativos sobre las intervenciones y luego se presentan las percepciones de los oficiales desde cuatro categorías inductivas que surgen del proceso de entrevistas: (1) pobreza, (2) percepción sobre el Departamento del Chocó, (3) explotación ilícita de yacimientos mineros y (4) estrategias desarrolladas por el Ejército Nacional (figura 4). 


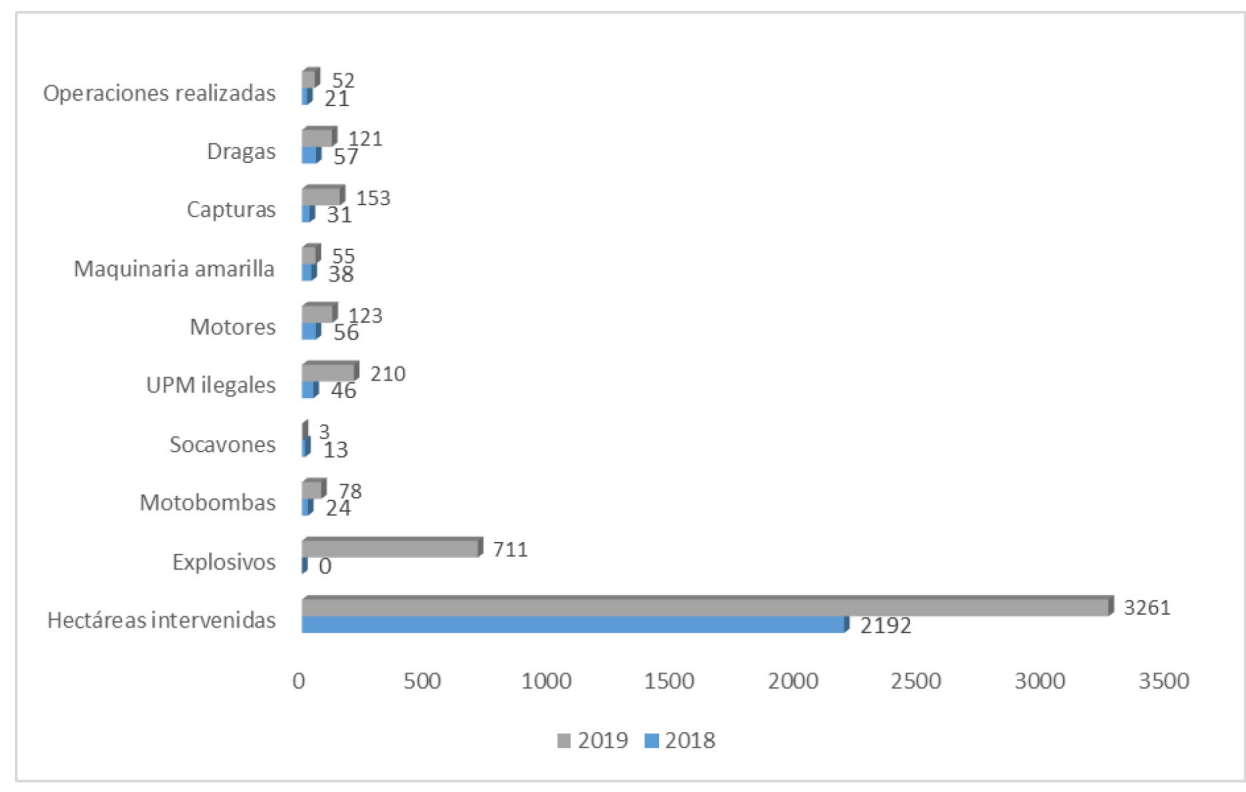

Figura 4. Actividades del Ejército Nacional contra la minería ilegal en los ańos 2018 y 2019.

Fuente: Elaborado por los autores con base en Departamento de Operaciones CEDEC13 (2019).

La figura 4 describe las actividades que el Ejército Nacional llevó a cabo en los años 2018 y 2019 con respecto a la minería ilegal en Colombia. La comparación se realiza a septiembre de ambos años para evitar sesgos. En términos generales, la mayoría de las acciones realizadas tuvieron un aumento importante. Así, la cantidad de hectáreas intervenidas se incrementó el $49 \%$; las motobombas decomisadas el $225 \%$; las Unidades de Producción Minera [UPM] ilegales el 357 \%; los motores el $120 \%$; la maquinaria amarilla el $45 \%$; la realización de capturas el $394 \%$; las dragas el $112 \%$ y las realizadas en total el $148 \%$. Asimismo, se observó un incremento importante en operaciones contra blancos tipo dragas y UPM ilegales debido al dańo ambiental que estas generan (Departamento de Operaciones CEDEC13, 2019).

Particularmente, la Séptima División del Ejército Nacional es la encargada de luchar contra la minería ilegal en el Departamento del Chocó. Esta división claramente es la más activa en cuanto a operaciones en contra de este flagelo. La Séptima División se encargó del $57 \%$ de las operaciones, $51 \%$ de las capturas, $88 \%$ de las UPM ilegales, $78 \%$ de las dragas, $65 \%$ de la maquinaria, $76 \%$ de los motores, $66 \%$ de las motobombas, $60 \%$ de los socavones, $18 \%$ de los explosivos y $98 \%$ del combustible del total en el país (figura 5). 


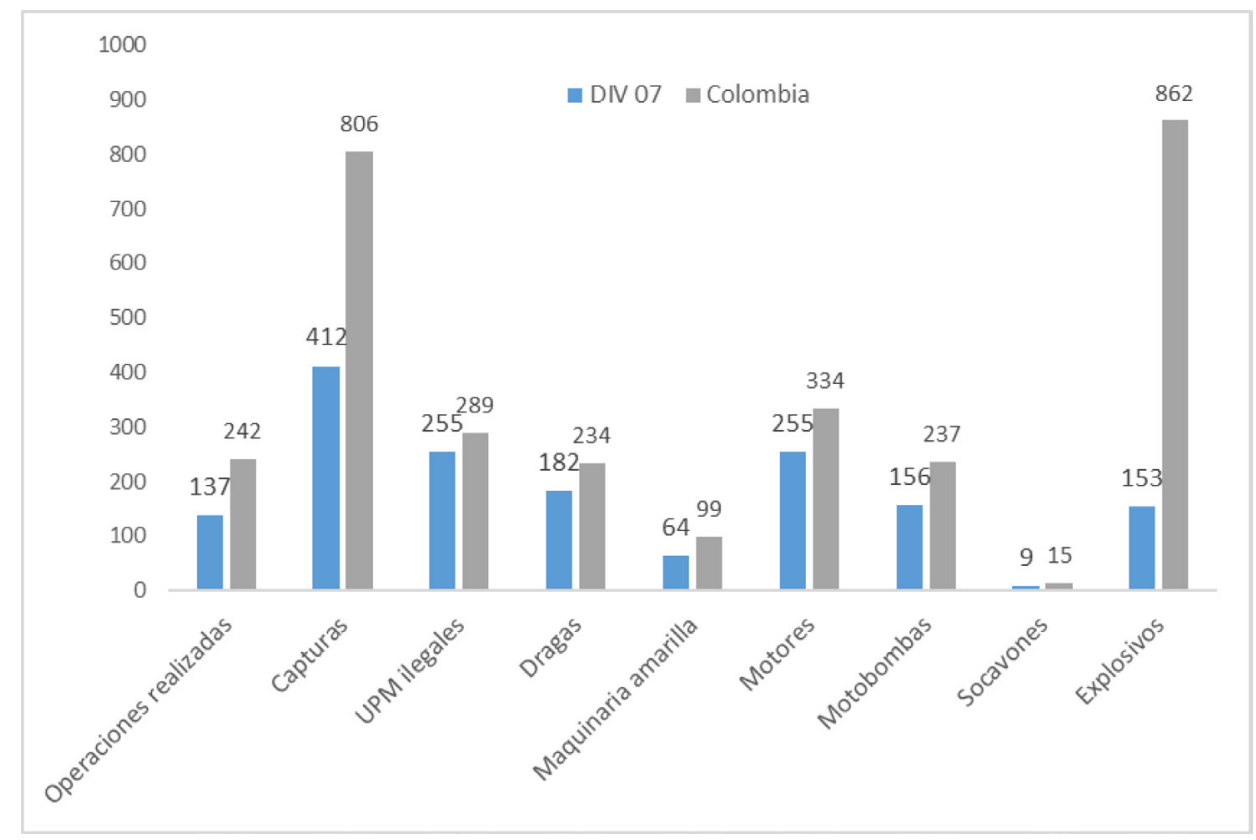

Figura 5. Actividades militares del Ejército Nacional contra la minería ilegal.

Fuente: Elaborado por los autores con base en Departamento de Operaciones CEDEC13 (2019).

\section{Percepciones de oficiales del Ejército Nacional frente a la pobreza y la minería ilegal}

Las percepciones de los tres oficiales que cumplen cargos de liderazgo en el Departamento del Chocó frente a la minería ilegal fueron analizadas a través del software AtlasTi. 7. A continuación se presentan los resultados con base en los esquemas de las cuatro categorías propuestas.

Según los oficiales entrevistados, la pobreza en el departamento se comprende como un problema claramente multidimensional, sobre el cual el Ejército Nacional ha desarrollado acciones de intervención militar social. Estos programas, liderados por el Comando de Apoyo de Acción Integral y Desarrollo del Ejército (CAAID), ha buscado implementar proyectos productivos y proteger el medio ambiente (figura 6). Si bien estas son acciones positivas, aún se necesitan acciones interinstitucionales y bastante articulación con empresas públicas y privadas para lograr consolidar estos propósitos. 


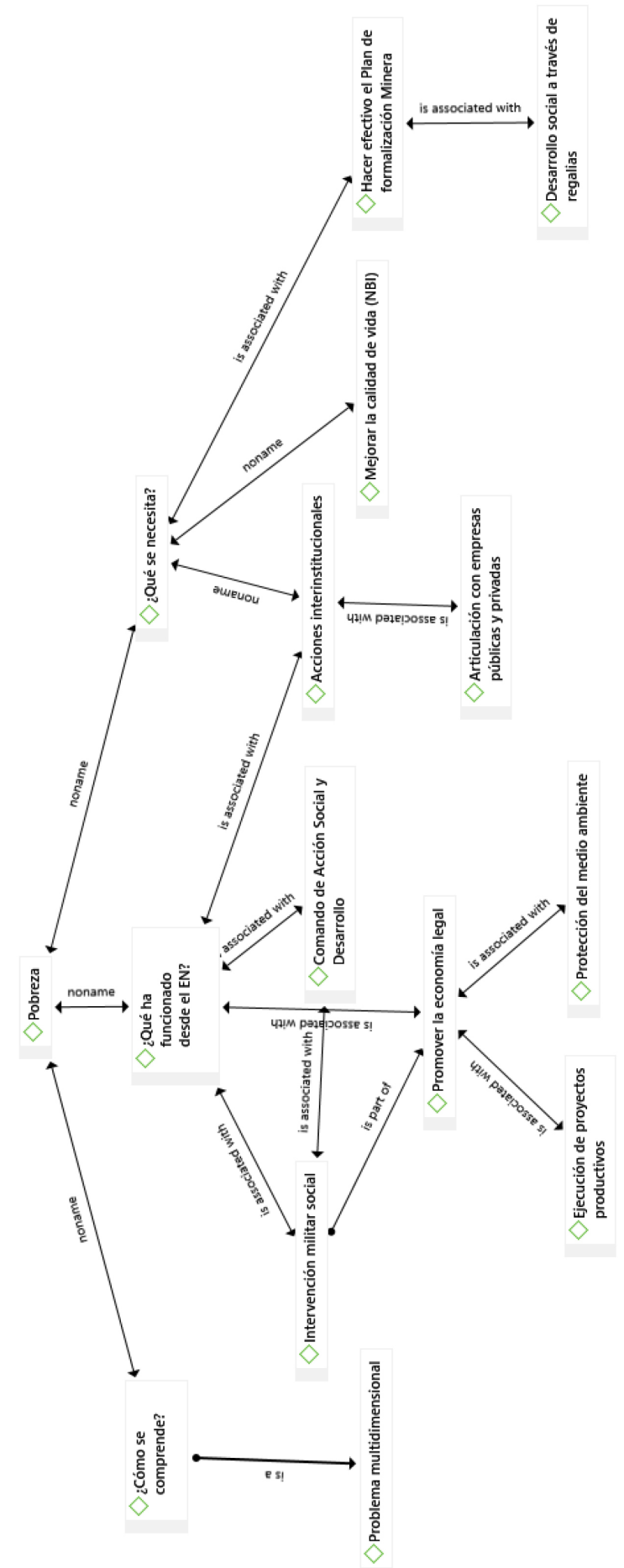

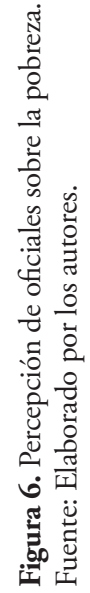


El Comando de Apoyo de Acción Integral y Desarrollo conduce las operaciones de Acción Integral y Desarrollo en el Ejército Nacional, en coordinación con entidades gubernamentales y no gubernamentales. De esta manera, integra las capacidades de la Fuerza con los asociados de la Acción Unificada, con lo cual genera las condiciones para promover la recuperación social del territorio en camino a la consolidación.

De igual forma, se considera que es imperativo realizar acciones que hagan efectivo el Plan de Formalización Minera, con el cual se pueden realizar programas sociales a través de las regalías. Con este conjunto de acciones, en últimas, se busca mejorar la calidad de vida de los pobladores.

La percepción de los oficiales del Ejército Nacional con experiencia en el Departamento del Chocó gira en torno a la región y al mismo actuar de la Fuerza. Respecto a la región, se percibe un gran potencial en el ámbito geopolítico, por cuanto existen límites internacionales con Panamá, se constituye como una vía potencialmente importante de acceso al mar desde otros departamentos y, finalmente, como una excelente fuente de turismo. Sin embargo, la percepción de la región en el ámbito social no es tan alentadora. Las razones son el alto índice de NBI, la corrupción, el desempleo, la educación de baja calidad, la presencia de grupos armados, la falta de institucionalidad y la sensación de que por parte del Estado solamente llega la represión (figura 7). Todos estos factores fomentan la ilegalidad en el departamento como consecuencia de la falta de oportunidades.

En el marco de esta percepción sobre la región, los oficiales afirman que la comunidad valora las acciones del Ejército Nacional en relación con su componente social, pero agregan que esta no ve con buenos ojos las operaciones militares por cuanto afectan su sustento diario. Al respecto, los oficiales consideran que el combate a la explotación ilícita de yacimientos mineros debe ser la primera fase antes de consolidar programas sociales y que, por supuesto, el Ejército Nacional tiene la fuerza para apoyar el desarrollo social, aun cuando no tenga los recursos y no se haya consolidado todavía la institucionalidad. En la voz de uno de los oficiales:

Actualmente en el territorio se encuentra la Séptima División, en la que se ubica las fuerzas conjuntas de tarea Titán y Aquiles. Tiene cinco brigadas. La Brigada 15, con responsabilidad en el Departamento del Chocó. La Séptima División del Ejército Nacional tiene como jurisdicción todo el Departamento del Chocó, todo el Departamento de Antioquia, todo el Departamento de Córdoba, parte del Departamento de Sucre, parte del Departamento de Santander y un municipio del Departamento de Boyacá. El área de operaciones de la Séptima División 


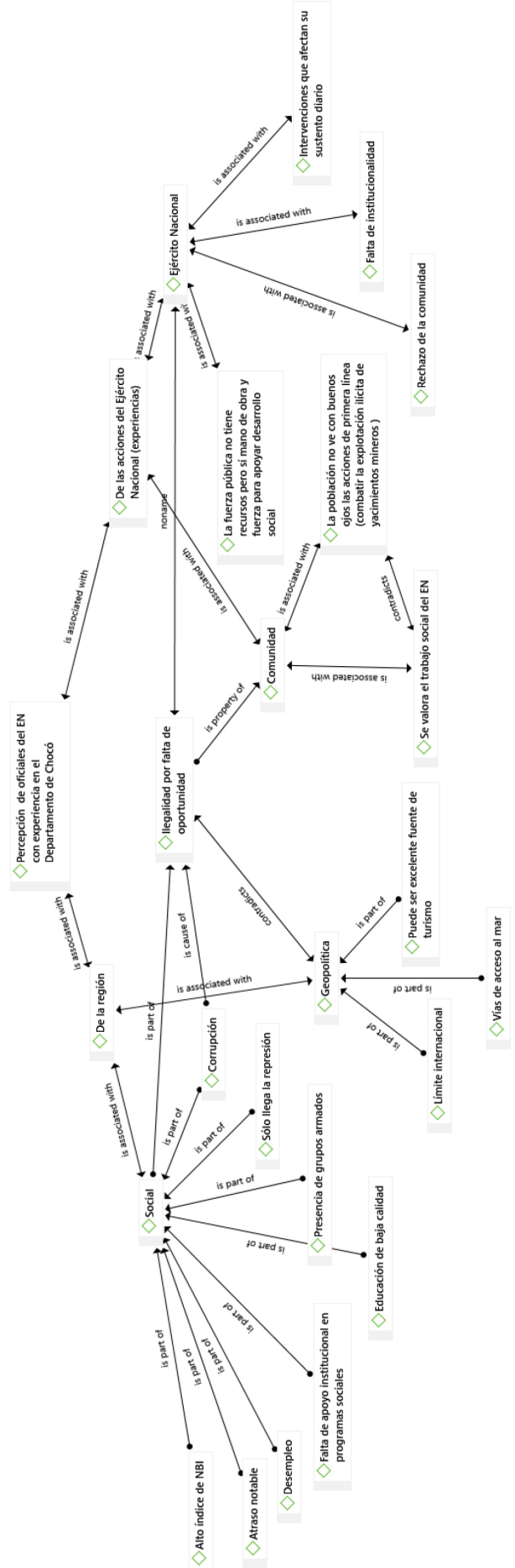

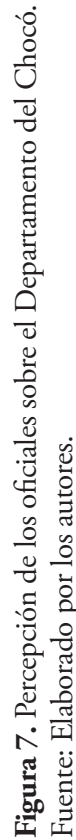


es sumamente importante para el país, en vista de que aporta el $25 \%$ de PIB, el $35 \%$ de energía para el país y el 32,4\% de producción de textiles. Existe riqueza de minerales [Chocó]. Uno de los aspectos críticos tiene que ver con que es el tercer punto de cultivos ilícitos donde hay más coca sembrada. Esta división posee actualmente 23.800 hombres, de manera que es la división que le aporta al Ejército Nacional el $47 \%$ de los resultados y representamos el $22 \%$ de los hombres del Ejército Nacional.

El Departamento del Chocó es rico en minerales y agua; esta línea de agua y biodiversidad representa uno de los intereses del actual gobierno del presidente Iván Duque y, por ende, la tarea de protección es efectiva. Es un departamento en el que el desarrollo ha sido débil por parte del Estado. Existe un nivel de inequidad importante, hay pobreza absoluta, y todo se da porque es un departamento que es fluvial y todo se mueve a través de los ríos, pero no cuenta con el desarrollo necesario. Hoy el Departamento del Chocó solo cuenta con dos vías de entrada terrestres [MedellínQuibdó y Pereira-Quibdó].

La parte norte del Chocó hasta Istmina depende mucho de Antioquia; y la parte sur depende del Valle. Ahí se puede ver que el poco desarrollo que ha tenido es porque esos departamentos le han entregado sus Necesidades Básicas como energía y agua potable a estas regiones del Chocó.

Hay presencia de grupos armados organizados en razón a que es el final de dos corredores de salida de las rentas ilícitas. Al norte está la salida al océano Atlántico y al sur al océano Pacífico. En la región del Atrato [Río Sucio-Acandí], se encuentra el grupo organizado del Clan del Golfo y de ELN, Frente de Guerra Occidental Omar Gómez, y en el sur están las estructuras de Urabá y Bloque Turbo.

En Chocó se puede hablar de más de 500 hombres alzados en armas del Clan del Golfo, y del ELN 400 hombres. Todos dedicados a cuidar las rutas de salida del narcotráfico y la minería ilegal.

Hay minería ilegal en el Chocó porque no cuentan con otros elementos de producción por parte de la población afro, indígena y campesina. Todo su sustento es el río; esto genera que la población empiece a hacer minería artesanal. Porque es lo que le da un sustento de vida a estos grupos poblacionales. En este sentido, el departamento se divide en tres partes: norte, que depende de la subregión de Urabá, y esa es su entrada a través de Dabeiba al río Atrato; sur, todo lo que da hacia San Juan, y centro, todo lo que da a Quibdó.

En este momento el ELN llegó al norte, antes estaba en el sur porque el norte lo tenía las FARC. Cuando hacen el acuerdo de paz se la entregan al ELN y por eso actualmente es tan fuerte la disputa que tienen con el Clan del Golfo por estas salidas de las rentas ilícitas. Hoy el ELN lo que hace es cobrar a empresas y pobladores que extraen minerales unos gravámenes. En el departamento se pagan las extorsiones con minerales; esto se ha visto cuando se hacen capturas de grupos armados ilegales porque se les encuentran elementos como oro, que son producto de ese pago de extorsiones. 
La mayor parte de las operaciones contra la explotación ilegal de los recursos mineros se presenta en el Departamento del Chocó. Esto se debe a unas características diferenciales del departamento que exacerban este flagelo. Entre estas características se encuentran la corrupción, la explotación laboral y la deserción escolar, cada una de las cuales disminuye las oportunidades de la población del Chocó para desarrollarse (figura 8).

Esto genera no solo un resentimiento por parte de las comunidades contra las instituciones del Estado, sino que también abre la posibilidad a la ilegalidad como forma de subsistencia y obtención rápida de recursos económicos. Esta dinámica cíclica estimula la explotación ilegal de recursos minerales y, consecuentemente, genera un daño ambiental que en últimas se traduce en un factor adicional de afectación social. Por ejemplo, la contaminación del agua disminuye su disponibilidad para el consumo humano y menoscaba aún más la calidad de vida de los chocoanos.

En el marco de las estrategias que el Ejército Nacional ha desarrollado para combatir la extracción ilegal de minerales se mencionaron diferentes acciones consideradas como efectivas. Entre estas se encuentran las de primera línea, es decir, aquellas dirigidas a la seguridad y defensa mediante operaciones militares, y dentro de estas, las de tipo terrestres por las capacidades de la Fuerza, principalmente. No obstante, también se mencionaron otras gestiones consideradas como de intervención militar social mediante la acción integral; una de las labores concretas en este sentido ha sido la articulación con instituciones, por ejemplo, con la Agencia de Desarrollo Rural, con la Agencia de los Estados Unidos para el Desarrollo Internacional [USAID, por su sigla en inglés] y con la creación del Comando de Acción Integral y Desarrollo (figura 9).

Precisamente, una de las estrategias del Ejército Nacional es establecer relaciones interinstitucionales con la empresa pública y privada, pero estas acciones deben ser unificadas y dirigidas a obtener resultados comunes para que puedan tener un verdadero impacto. Actualmente se está realizando la articulación a partir del Programa Fe en Colombia, el cual se focaliza en conectar la oferta estatal y privada con las comunidades que más apoyo necesitan en el desarrollo de sus proyectos. Esto se hace considerando los roles legales de diferentes instituciones. Ejemplo de ello es la Sentencia T-622 de 2016, de la Corte Constitucional.

Específicamente, la sentencia ordena desarrollar un plan de acción conjunto para neutralizar y erradicar definitivamente las actividades de minería ilegal en el Atrato y demás afluentes del Chocó. Los responsables de este plan son el Ministerio de Defensa, la Policía Nacional —Unidad Contra Minería Ilegal—, el Ejército 


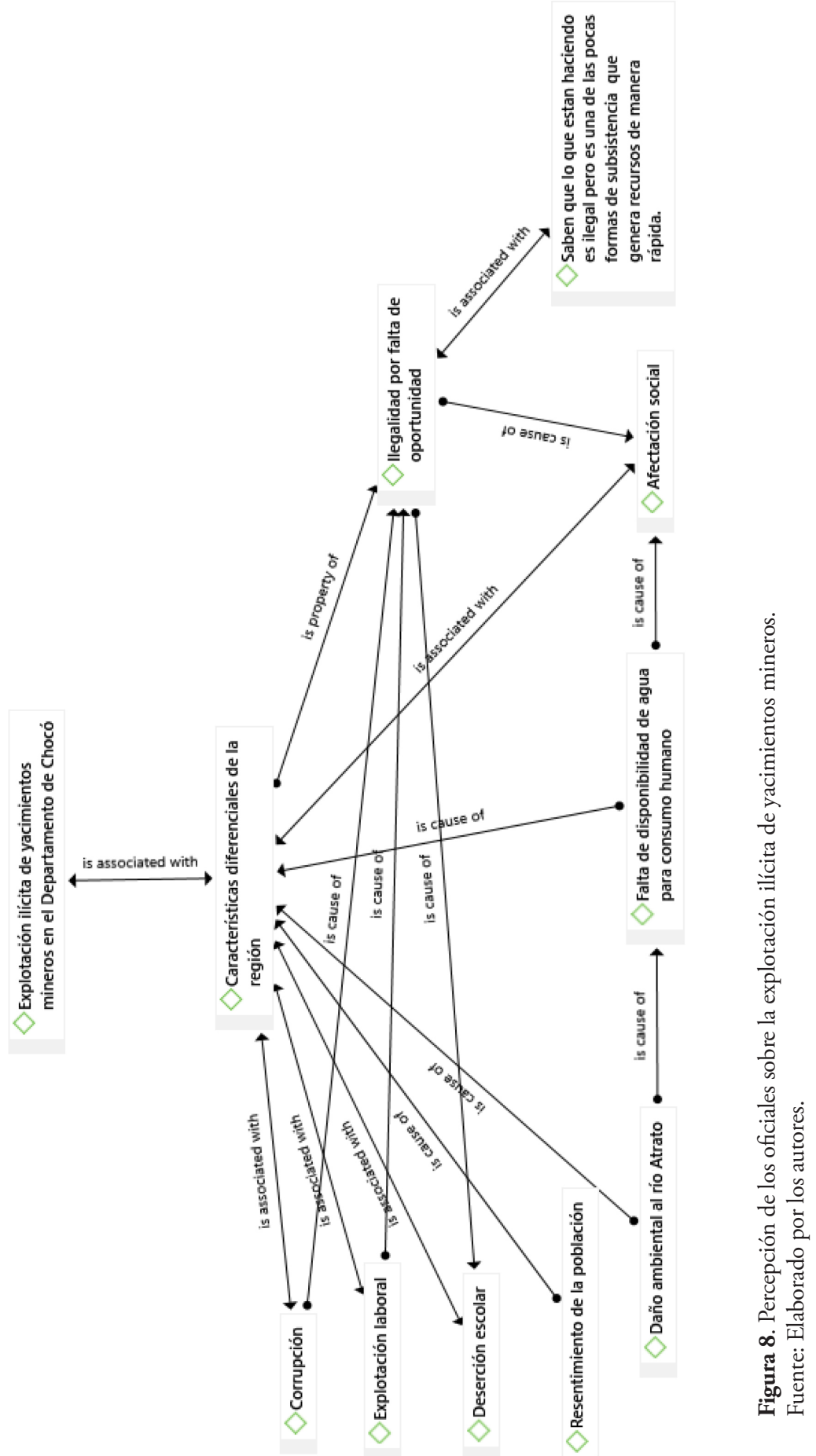




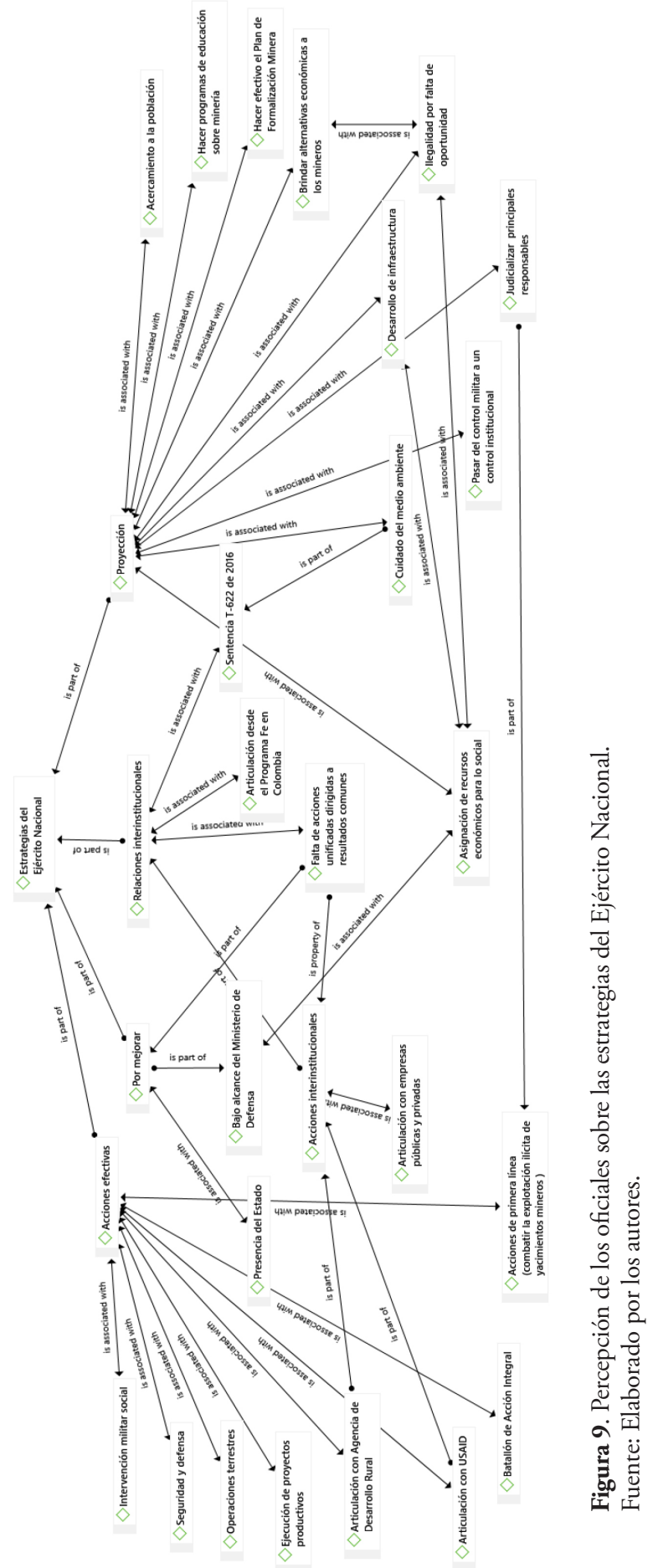


Nacional, la Fiscalía, las gobernaciones y los municipios con el acompañamiento del Ministerio de Relaciones Exteriores y en conjunto con las comunidades.

La poca presencia del Estado y el poco alcance del Ministerio de Defensa para ejercer un control territorial efectivo, junto con la falta de una real acción unificada dirigida a resultados comunes, son aspectos clave que se deben mejorar dentro de la estrategia del Ejército Nacional contra la explotación ilegal de los recursos mineros.

Así las cosas, la proyección de esta estrategia se debe orientar a disminuir la ilegalidad originada por la falta de oportunidades para la población civil. Para esto, se debe pasar del control militar a un posterior control institucional, tal como lo manifiesta la Política de Defensa y Seguridad (Ministerio de Defensa Nacional, 2019) del actual gobierno nacional. Asimismo, es necesario que, por supuesto, continúen las acciones de primera línea mediante las operaciones militares para judicializar a los principales responsables (Miron, 2019a, 2019b), pero también para contribuir al cuidado del medio ambiente y la generación de programas de acercamiento a la población. Entre estos se encuentran los programas de educación sobre minería, mediante los cuales no solo se haría efectivo el Plan de Formalización de la Minería, sino también se brindarían alternativas económicas a los mineros. No obstante, estos planes requieren recursos para cerrar las brechas entre las instituciones y lograr los objetivos comunes proyectados.

\section{Las estrategias...}

A partir de las entrevistas realizadas a los oficiales del Ejército Nacional y de su análisis, se determinaron dos estrategias que se han realizado de forma continua y que pueden tener un efecto sobre las condiciones asociadas a la pobreza en el Departamento del Chocó. Estas estrategias, que se articulan entre sí, se listan a continuación.

En primer lugar, se encuentran las acciones de primera línea, es decir, ¿cómo se desarrollan las operaciones militares en el Chocó? Las operaciones militares contra la extracción de minerales se hacen con acciones que tiene la Brigada contra la minería ilegal. Esta Brigada es un Estado Mayor que planea con la Brigada 15 y la Fuerza de Tarea Titán las operaciones militares que se van a realizar. Sin embargo, la destrucción de la maquinaria solo le corresponde a la Policía Nacional, de modo que las operaciones solo se pueden hacer con la Policía Nacional para que ellos hagan el proceso de judicialización.

La acción integral en Chocó es una de las líneas de intervención, pero las gestiones principales deben ser de tipo militar. En esta región el Ejército Nacional 
tiene algunas limitaciones, especialmente debido a la restringida capacidad del transporte fluvial, lo cual afecta la neutralización de los insurgentes; en palabras de uno de sus miembros, "ellos allá se mueren de viejos". Además, actualmente se tiene un recorte en horas de vuelo y por eso no se ha logrado la eficiencia necesaria.

En segundo lugar, se encuentra la intervención militar de tipo social. A partir de la información recolectada, a continuación, se define cada una de estas estrategias:

1. Acciones de primera línea. Esta estrategia encierra todas las acciones tendientes a combatir la explotación ilícita de yacimientos mineros, que incluyen principalmente operaciones terrestres y, en menor medida, operaciones fluviales en razón a las limitaciones expuestas. Corresponde a capturas, neutralización de unidades de producción mineras ilegales, destrucción de dragas, maquinaria amarilla, motores, motobombas, socavones e incautación de explosivos y de combustible.

Esta estrategia que desarrolla el Ejército Nacional en el Departamento del Chocó es la de mayor envergadura, no solo con respecto a la otra estrategia, sino también con respecto a este mismo tipo de acciones en todo el país. De hecho, los resultados de esta estrategia se incrementaron de forma importante en el año 2019.

2. Intervención militar social. Esta estrategia es liderada por el Comando de Acción Integral y Desarrollo (CAAID) del Ejército Nacional de Colombia desde comienzos del año 2017. Su propósito es promover y llevar a cabo actividades que mejoren las condiciones de vida de las comunidades. Las acciones particulares de este comando están dirigidas a realizar jornadas de apoyo al desarrollo de ruedas de negocio, a la generación de ingresos, a la gestión interinstitucional que reúna aportes para proyectos de infraestructura, y a jornadas de fortalecimiento institucional.

El CAAID está compuesto por dos brigadas, una de las cuales tiene en su jurisdicción al Departamento del Chocó: la Brigada de Apoyo de Acción Integral y Desarrollo N. ${ }^{\circ}$. La misión de esta brigada es velar por que sus unidades dispongan de los recursos y estructuras asesoras para avanzar en la construcción del tejido social en cada una de sus jurisdicciones, de manera adecuada y eficiente para cumplir este lineamiento del gobierno nacional.

Con el direccionamiento del CAAID se desarrolla el Programa Fe en Colombia, el cual ha surgido en el Ejército Nacional como respuesta a la 
necesidad observada de articular la oferta estatal y las posibilidades ofrecidas por la empresa privada y la cooperación internacional para fortalecer los procesos de desarrollo territorial en las regiones.

Dentro de las acciones que destacaron los oficiales entrevistados se encuentra el desarrollo de proyectos productivos y los procesos de articulación interinstitucional, especialmente con la USAID, la Agencia de Desarrollo Rural y la empresa pública y privada.

\section{Relación entre las acciones del Ejército Nacional contra la minería ilegal y su efecto potencial sobre las condiciones sociales asociadas a la pobreza del Departamento del Chocó}

Para desarrollar el tercer objetivo se analizaron las dos estrategias que el Ejército Nacional implementa en el desarrollo de sus labores contra la explotación ilegal de recursos mineros, las cuales se identificaron en el segundo objetivo con cada una de las once condiciones sociales asociadas a la pobreza que inciden en la minería ilegal en el Chocó, reconocidas en el primer objetivo (tabla 2).

Tabla 2. Relación entre las acciones del Ejército Nacional y el efecto potencial sobre las condiciones sociales asociadas a la pobreza

\begin{tabular}{lll}
\hline \multicolumn{1}{c}{ Condiciones sociales } & \multicolumn{1}{c}{ Estrategias } \\
\hline Falta de redes de protección social & $\begin{array}{c}\text { Acciones de } \\
\text { primera línea }\end{array}$ & $\begin{array}{c}\text { Intervención } \\
\text { militar social }\end{array}$ \\
Competencia en el uso de la biodiversidad & $\mathrm{x}$ & $\mathrm{x}$ \\
Desigualdad & $\mathrm{x}$ \\
Violación de los Derechos Humanos & $\mathrm{x}$ & $\mathrm{x}$ \\
Violación de los derechos laborales & $\mathrm{x}$ & $\mathrm{x}$ \\
Desplazamiento forzado & $\mathrm{x}$ & $\mathrm{x}$ \\
Competencia en el uso de la tierra & $\mathrm{x}$ & \\
\hline
\end{tabular}




\begin{tabular}{lcc}
\hline \multicolumn{1}{c}{ Condiciones sociales } & Estrategias \\
\hline \multicolumn{1}{c}{$\begin{array}{c}\text { Acciones de } \\
\text { primera línea }\end{array}$} & $\begin{array}{c}\text { Intervención } \\
\text { militar social }\end{array}$ \\
\hline Corrupción en las instituciones & $\mathrm{x}$ \\
Disfunción de la gobernanza & $\mathrm{x}$ \\
Falta de desarrollo sostenible & $\mathrm{x}$ \\
Falta de servicios sanitarios de calidad & $\mathrm{x}$ \\
\hline
\end{tabular}

Fuente: Elaborado por los autores.

\section{Falta de redes de protección social}

Como se ha descrito anteriormente, el Departamento del Chocó tiene fuertes carencias en cuanto a la capacidad institucional de llegar a las comunidades vulnerables con programas que reduzcan la brecha de la pobreza. Esta condición social ocasiona la falta de oportunidades educativas y de empleo, lo cual, de forma indirecta, genera deserción y aumenta la posibilidad de reclutamiento en grupos armados ilegales o el ingreso a actividades económicas ilegales, que a su vez estimula el conflicto armado y la violencia.

En este sentido, las acciones de intervención militar social tienen un efecto más determinante por cuanto buscan mejorar la comunicación interinstitucional. Sin embargo, cabe resaltar que este aspecto aún es débil y requiere de mayores esfuerzos y recursos económicos. Asimismo, las acciones de primera línea del Ejército Nacional tienen mayor impacto en disminuir los efectos negativos del conflicto armado y la violencia, aun cuando esto no sea percibido positivamente por la comunidad porque implica la reducción de ingresos económicos inmediatos.

\section{Competencia en el uso de la biodiversidad}

La gran biodiversidad contenida en los ecosistemas chocoanos, una de las mayores del mundo, contrasta con los altos niveles de pobreza de la región. Esta biodiversidad también es reflejo de la riqueza cultural, mineral e hídrica del Chocó. La institucionalidad y el tipo de recursos disputados son clave y determinan la dinámica del conflicto (Rettberg \& Ortiz, 2014).

En el caso del Departamento del Chocó, los dos factores mencionados potencian las actividades de explotación ilegal de la riqueza natural y, por lo tanto, el conflicto. Las acciones de primera línea son determinantes para mitigar la pérdida 
de la riqueza de la región, pues los diferentes actores que disputan los recursos naturales en la región tienen fuerte presencia allí. Por su parte, la intervención militar social, es decir, las acciones que fomentan la institucionalidad, la conservación del medio ambiente y el Plan de Formalización Minera, tiene un potencial importante para garantizar la sostenibilidad de las actividades de primera línea.

\section{La desigualdad}

El Departamento del Chocó presentó en el 2018 el coeficiente de Gini más alto de Colombia (0,579). El coeficiente de Gini es el indicador que se utiliza con mayor frecuencia para medir el grado de desigualdad en la distribución del ingreso, de manera que esta cifra refleja la grave situación económica de los habitantes del departamento. La desigualdad, al ser causante de la falta de oportunidades educativas y laborales, exacerba la violencia y las economías ilegales, como es el caso de la minería ilegal.

Particularmente, esta condición determina la importancia que tienen las dos estrategias con las que el Ejército Nacional enfrenta la minería ilegal. Las acciones de primera línea - la captura de cabecillas y la destrucción de maquinaria, entre muchas otras - buscan desmotivar la explotación ilegal de yacimientos mineros, lo cual permite que posteriormente se pueda realizar la intervención militar social y obtener una mayor confianza de la población en sus instituciones.

\section{Violación de los Derechos Humanos}

La violación de los Derechos Humanos, probablemente la condición más transversal de las analizadas en este documento, es consecuencia directa de la situación social, económica y política del Departamento del Chocó. Por su carácter transversal, la violación de los Derechos Humanos es sin duda un aspecto determinante en cada uno de los componentes del mecanismo explicativo de la pobreza en el Chocó. Dado que la minería ilegal estimula la violación de los Derechos Humanos de forma directa, la implementación del Plan de Formalización Minera sería una estrategia positiva para disminuir este fenómeno.

Las acciones de primera línea y la intervención militar social buscan, desde diferentes aproximaciones, restablecer los derechos de la población a través del mejoramiento de las condiciones básicas de vida. Los oficiales entrevistados consideran que debe haber inicialmente un control militar que migre posteriormente a un manejo institucional. Esto contribuiría a disminuir la violación de los Derechos Humanos asociada a la minería ilegal en el Chocó. Desafortunadamente, hoy en 
día la población no percibe como una realidad el manejo institucional. De hecho, la mayor cantidad de intervenciones se concentran en las acciones de primera línea y en labores de seguridad y defensa, pues la presencia del Estado sigue siendo un aspecto por mejorar.

\section{Violación de los derechos laborales}

El irrespeto de los atributos de dignidad vinculados con valores materiales y con las formas de sustento o de ingreso de las personas en el Chocó es evidente. El primer puesto que ostenta el Departamento del Chocó con respecto a la tasa de desempleo es un reflejo de ello. Adicionalmente, resulta interesante que el oro represente el 91,6\% de las exportaciones del departamento y que las partes para máquinas fueran los principales productos de importación entre 2016 y 2017 . No obstante, la formalización minera y las alternativas económicas frente a la minería aún no son una realidad. Este panorama sugiere el vínculo que existe entre la minería ilegal y la violación de los derechos laborales.

La falta de oportunidades laborales explica por qué la población no ve con buenos ojos las acciones del Ejército Nacional para combatir la minería ilegal, aunque, como se ha mencionado, la intervención militar social es más valorada. Esta percepción positiva se puede explicar porque esta estrategia propicia y coordina las distintas posibilidades que generan las acciones interinstitucionales. Por ejemplo, la posibilidad de realizar proyectos productivos con el acompańamiento de la Agencia de Desarrollo Rural y USAID se considera una propuesta prometedora que brinda alternativas económicas. Lastimosamente, para estas acciones aún se necesita mayor asignación de recursos y desarrollo de la infraestructura.

\section{Desplazamiento forzado}

Se estima que 4.873 personas han sido desplazadas, pertenecientes a comunidades indígenas y afrocolombianas. El 53,8 \% fue a causa de grupos armados posdesmovilizados, y el 46,1 \% fue a causa del ELN. Estas cifras dan cuenta de la importancia que reviste la intervención militar social, pues una intervención del Ejército Nacional centrada solamente en las acciones de primera línea podría incrementar el rechazo de las comunidades. Por consiguiente, las labores de acercamiento que realiza el CAAID, con el propósito de mejorar las condiciones de vida de las comunidades y alejarlas de las actividades económicas ilegales, constituyen iniciativas importantes por cuanto abren la posibilidad a oportunidades educativas y de empleo. Sin embargo, estas acciones no están completamente consolidadas en la región. 


\section{Competencia en el uso de la tierra}

La falta de oportunidades en el departamento del Chocó, tanto educativas como de empleo, así como el conflicto armado, obligan a la población a acudir a las alternativas que ofrece su entorno. Así, la tierra se vuelve un medio de obtención de recursos que se puede explotar, independientemente de la ilegalidad con la que se haga. Para enfrentar esta situación se requieren las acciones disuasivas de primera línea, pero indudablemente también de la institucionalidad del Estado. De lo contrario, las poblaciones perciben del Estado solamente la represión y se generan sentimientos de rechazo, lo que en últimas puede alimentar la violencia, el conflicto y, por supuesto, las actividades extractivas ilegales. En este punto, la intervención militar social es una estrategia pertinente y muy necesaria en la región.

\section{Corrupción en las instituciones}

El alto índice de NBI, el atraso notable, el desempleo y la educación de baja calidad son factores que se asocian a la corrupción en las instituciones. Esta situación motiva la "ilegalidad por falta de oportunidad" y el rechazo de las comunidades hacia las instituciones, lo cual se transforma en el combustible necesario para el conflicto y las economías ilegales. Esta falta de oportunidades, sumada al rechazo de la comunidad y al accionar del Ejército Nacional sobre la minería ilegal, ejercen una gran presión sobre la población debido a que las intervenciones del Ejército Nacional afectan el sustento diario de muchas personas.

De esta forma, la intervención militar social mediante la ejecución de proyectos productivos y las acciones interinstitucionales no solamente son un primer acercamiento a lo que debería ser la presencia del Estado más allá de lo que se conoce como "la bota militar", sino que además resultan favorables para disminuir la presión y facilitar una transición a economías legales.

\section{Disfunción de la gobernanza}

Esta condición del Departamento del Chocó ha originado históricamente una profunda deuda con la comunidad a raíz de una cíclica y permanente falta de oportunidades en los ámbitos educativo y laboral, la cual ha incentivado indirectamente el conflicto armado y ha permitido que la minería ilegal aumente. Dado que en muchos casos constituye la única institución que representa al Estado al implementar las estrategias de primera línea y la intervención militar social, el Ejército Nacional comienza a realizar acercamientos que, al ser integrales, probablemente permitan un impacto mayor y más sostenible de su función. Las acciones sociales, la 
infraestructura, el cuidado del ambiente y la generación de oportunidades podrían romper los círculos viciosos de falta de oportunidades, que hasta hace poco tiempo solo se atendían con acciones de primera línea.

\section{Falta de desarrollo sostenible}

De forma consistente con lo que se mencionó en el párrafo anterior, la sostenibilidad en el Departamento del Chocó es resultado de acercamientos integrales y articulados de las instituciones. La falta de desarrollo sostenible, al ser consecuencia, pero también causa de la falta de oportunidades y del fomento de economías ilegales, debe ser uno de los objetivos de las acciones que se realicen en el campo social e interinstitucional. Así, la articulación entre Estado, empresas privadas y organizaciones internacionales es determinante en este propósito (Quintero, 2020). No obstante, esto no se consolida todavía.

\section{Falta de servicios sanitarios de calidad}

Esta condición característica del Departamento del Chocó es importante, en la medida en que es consecuencia de la falta de oportunidades educativas y de empleo, así como de las malas políticas gubernamentales y del conflicto armado. En este sentido, es un reflejo de la crisis del departamento. Por consiguiente, las acciones del Ejército Nacional pueden impactar de manera indirecta esta problemática, especialmente por el efecto social que puedan obtener.

Para finalizar, es importante resaltar que todas las condiciones sociales analizadas en este documento son consecuencia de las malas políticas gubernamentales y que, por lo tanto, el Departamento del Chocó requiere de una mayor presencia del Estado, incluso más allá de las capacidades del Ejército Nacional.

\section{Conclusión}

La explotación ilegal de yacimientos mineros, o minería ilegal, es un fenómeno complejo de vieja data que actualmente afecta al Departamento del Chocó de manera directa en muchos ámbitos sociales. Según las investigaciones revisadas, el principal motivo que lleva a las familias a dedicarse a esta actividad es la falta de oportunidades laborales y educativas, por lo cual este oficio representa una tradición en el territorio.

En este estudio se empleó un mecanismo explicativo de la pobreza para describir este fenómeno en el Chocó. Los componentes de este mecanismo son la 
falta de oportunidades educativas y de empleo, el conflicto armado y la violencia, así como las malas políticas gubernamentales, las cuales originaron en todos los casos las condiciones sociales asociadas a la pobreza que inciden en la minería ilegal.

En este trabajo se estableció que el Ejército Nacional cuenta principalmente con dos estrategias de intervención para hacer frente a la minería ilegal: las acciones de primera línea y la intervención militar social. Estas estrategias incluyen una serie de acciones que tienen un efecto determinante sobre las condiciones sociales asociadas a la pobreza que inciden en la minería ilegal.

$\mathrm{Si}$ bien las estrategias integrales pueden fortalecer el impacto que tienen las acciones del Ejército Nacional en mejorar las condiciones sociales en los habitantes del Departamento del Chocó, todavía es necesario avanzar en la articulación institucional y el mejoramiento de las políticas gubernamentales orientadas a corregir la disfunción de la gobernanza y a mejorar el desarrollo sostenible de la región.

Las estrategias de intervención militar social en el Departamento del Chocó son aún de poco alcance para la magnitud de los problemas que tiene. Si bien no se trata de que el Ejército Nacional supla las funciones del Estado, sí es necesario que tenga un mayor acercamiento a las problemáticas sociales y a la población, así como que reciba cualificación para lograr resultados de mayor impacto.

\section{Conflicto de intereses}

Los autores declaran que no existe ningún potencial conflicto de interés relacionado con este capítulo.

\section{Financiación}

Los autores no declaran fuente de financiamiento para la realización de este capítulo.

\section{Referencias}

Ba, F. A. (2014). The effects of illegal small-scale gold mining ("galamsey") activities on the water quality of the Akantansu and Sintim Rivers in the Asutifi North District of the Brong Ahafo Region of Ghana. University of Nkrumah.

Berdal, M. R., \& Malone, D. (Eds.). (2000). Greed \& grievance: Economic agendas in civil wars. Lynne Rienner Publishers.

Bermúdez Tapia, M. A., Sierra-Zamora, P. A., \& Fernández Osorio, A. E. (Eds.). (2020a). La tutela de derechos individuales y colectivos en el estado de derecho. Sello Editorial ESMIC. 
Bermúdez Tapia, M. A., Sierra-Zamora, P. A., \& Fernández Osorio, A. E. (Eds.). (2020b). El Estado ante emergencias sociales. Sello Editorial ESMIC.

Broman, G. I., \& Robèrt, K. H. (2017). Un marco para el desarrollo estratégico sostenible. Journal of Cleaner Production, 140, 17-31.

Castillo, J., \& Cárdenas, A. (2012). Estado del arte para determinar la viabilidad de una póliza ambiental en el sector minero colombiano. Boletin Semillas Ambientales, 6(2), 17-24. https:// revistas.udistrital.edu.co/index.php/bsa/article/view/9368/10574

Collier, P., \& Hoeffler, A. (2005). Rentas de recursos, gobernanza y conflicto. Diario de Resolución de Conflictos, 49(4), 625-633.

Consejo Privado de Competitividad. (2018). Índice Departamental de Competitividad. https:// compite.com.co/indice-departamental-de-competitividad/

Corredor, C. (1999). El problema de la pobreza: una reflexión conceptual. En Consuelo Corredor (Ed.), Pobreza y desigualdad: reflexiones conceptuales y medición (pp. 39-68). CINEP; Colciencias; Universidad Nacional de Colombia.

Datt, D. (2016). Inter-governmental political relations in a federation and illegal mining of natural resources. Environmental Economics and Policy Studies, 18(4), 557-576.

Defensoría del Pueblo (s. f.). ¿Qué son los Derechos Humanos? https://www.defensoria.gov.co/public/ Normograma\%202013_html/Normas/Guia_Inducc_Cartilla_3.pdf

Defensoría del Pueblo. (2017). Informe especial. Grupos armados ilegales y nuevos escenarios de riesgo en el posacuerdo. http://www.defensoria.gov.co/public/pdf/economiasilegales.pdf

Defensoría del Pueblo. (2019). Minería ilegal, conflicto armado y vulneración al medio ambiente. http://www.defensoria.gov.co/public/pdf/economiasilegales.pdf

Departamento Administrativo Nacional de Estadística [DANE]. (2018). Boletín técnico sobre pobreza monetaria departamental. https:/www.dane.gov.co/files/investigaciones/condiciones_vida/ pobreza/2018/bt_pobreza_monetaria_18.pdf

Departamento Administrativo Nacional de Estadística [DANE]. (2019). Principales indicadores del mercado laboral, julio de 2019. https://www.dane.gov.co/files/investigaciones/boletines/ech/ ech/bol_empleo_jul_19.pdf

Departamento de Operaciones CEDEC13. (2019). Cartilla operacional del comandante. Ejército Nacional de Colombia.

DiJohn, J. (2006). Abundancia de recursos minerales y conflicto político violento: una evaluación critica del modelo de Estado rentista. Nuestra guerra sin nombre. Universidad Nacional de Colombia.

Dorado, A. (2010). ¿Qué es la biodiversidad? Una publicación para entender su importancia, su valor y los beneficios que nos aporta. Fundación Biodiversidad. http://www.ecomilenio.es/wp-content/ uploads/2010/10/que-es-la-biodiversidad-web.pdf

Duff, P. M., \& Downs, T. J. (2019). Frontline narratives on sustainable development challenges/ opportunities in the 'illegal' gold mining region of Madre de Dios, Peru: Informing an integrative collaborative response. The Extractive Industries and Society, 6(2), 552-561.

Edelman, B., Luca, M., \& Svirsky, D. (2017). Discriminación racial en la economía colaborativa: evidencia de un experimento de campo. American Economic Journal: Applied Economics, 9(2), 1-22.

EEC. (1985). On specific community action to combat poverty (Council Decision of 19 December 1984), 85/8/EEC. Official Journal of the EEC, 2(24). 
Egmann, G., Tattevin, P., Palancade, R., \& Nacher, M. (2018). Prehospital emergencies in illegal gold mining sites in French Guiana. Wilderness and Environmental Medicine, 29(1), 72-77.

Elbadawi, E., \& Sambanis, N. (2000). ¿Por qué hay tantas guerras civiles en África? Comprender y prevenir conflictos violentos. Journal of African Economies, 9(3), 244-269.

Escobedo, R., \& Guío, N. (2015). Oro, crimen organizado y guerrillas en Quibdó. Fundación Ideas para la Paz. http://www. ideaspaz. org/publications/posts/1154

Eurosur, (s. f.). Causas y supresión de la pobreza. http://www.eurosur.org/futuro/fut47.htm

Fedesarrollo. (2008). La minería en Colombia: Impacto socioeconómico y fiscal. Fedesarrollo.

Gallego Duque, L. M. (2009). Acercamiento al problema social de la pobreza de las nociones de pobreza y los mecanismos causales. Revista de Trabajo Social, 9, 1-29. https://revistas.udea.edu. co/index.php/revistraso/article/view/5277/4638

Galvis-Aponte, L. A., Moyano, L. M., \& Alba-Fajardo, C. A. (2016). La persistencia de la pobreza en el Pacífico colombiano y sus factores asociados. Documentos de Trabajo Sobre Economía Regional y Urbana, 238. https://www.banrep.gov.co/docum/Lectura_finanzas/pdf/dtser_238.pdf

Gobernación del Chocó. (2017). Plan estratégico de mejoramiento de la calidad educativa en el Departamento del Chocó (2017-2027). https://www.utch.edu.co/portal/images/Plan-deMejoramiento-de-la-calidad-listo.pdf

Kervankiran, I., Dziwornu, M., \& Temurçin, K. (2016). Illegal mining as threat to sustainable development in Ghana. ZfWT, 8(3), 173-191.

Le Billon, P. (2000). La economía política de guerra de Angola: el papel del petróleo y los diamantes, 1975-2000. Asuntos Africanos, 100(398), 55-80.

La lucha contra la minería ilegal, un esfuerzo conjunto. (2018, julio 14). Semana. https://www.semana. $\mathrm{com} /$ contenidos-editoriales/fuerzas-armadas-marcha-hacia-la-paz/articulo/la-lucha-contra-la-mineria-ilegal-en- colombia/574844

Neil, A., Slee, D., Birss, M., Lefebvre, S., \& Bauer, B. (2011). Minería en Colombia: ‘a qué precio? https://www.peacebrigades.org/fileadmin/user_files/projects/colombia/files/colomPBIa/111122_ boletin_final_web.pdf

Mackenbach, J. P., Valverde, J. R., Bopp, M., Brønnum-Hansen, H., Deboosere, P., Kalediene, R., Kovács, K., Leinsalu, M., Martikainen, P. Menvielle, G., \& Regidor, E. (2019). Determinants of inequalities in life expectancy: an international comparative study of eight risk factors. The Lancet Public Health, 4(10), e529-e537.

Ministerio de Defensa Nacional. (2019). Política de Defensa y Seguridad (PDS). http://www. indepaz.org.co/wp-content/uploads/2019/08/POL\%C3\%8DTICA-DE-DEFENSA-PDSMindefensa.pdf

Miron, M. (2019a). Counterinsurgency Operations in the 21st Century: Insights from the U.S. Army Experiences in Iraq. Sello Editorial ESMIC.

Miron, M. (2019b). Counterinsurgency Theory and Practice: From Early Renaissance to Present Day. Sello Editorial ESMIC.

Oficina de las Naciones Contra las Drogas y el Delito [PNUD]. (2011). Informe nacional de desarrollo humano. Colombia rural: razones para la esperanza. PNUD.

Organización de las Naciones Unidas [ONU]. (1994). Consejo Económico y Social de la Organización de las Naciones Unidas, Comité de Recursos Naturales. Decisión 1994/308. 
Quintero Cordero, S. P. (2020). La cooperación internacional e intervención en escenarios de posconflicto. Sello Editorial ESMIC.

Rettberg, A., \& Ortiz, J. F. (2014). Conflicto dorado: canales y mecanismos de la relación entre minería de oro, conflicto armado y criminalidad en Colombia. Universidad de los Andes.

Rodríguez Albor, G., Peláez Blandón, M., \& García Luna, R. (2014). Inversión canadiense en Colombia: un análisis de las empresas extractivas. Revista de Economía del Caribe, 14. http:// rcientificas.uninorte.edu.co/index.php/economia/article/view/7063/6569

Samuel, A., Oladejo, N., \& Adetunde, I. (2012). The impact and effect of illegal mining (galamsey) towards the socio-economic development of mining communities: A case study of Kenyasi in the Brong Ahafo Region. International Journal of Modern Social Sciences, 1(1), 38-55.

Serrano, A., Martínez, M., \& Fonseca, L. (2016). Diagnóstico y caracterización de la minería ilegal en el municipio de Sogamoso, hacia la construcción de estrategias para la sustitución de la minería ilegal diagnosis. Tendencias, 1, 104-119. http://www.scielo.org.co/pdf/tend/v17n1/v17n1a06. pdf

Sierra-Zamora, P. A., Bermúdez Tapia, M. A., \& Arango Calderón, I. Y. (Eds.). (2020a). Elementos judiciales y procesales en contextos de cambios sociales. Sello Editorial ESMIC.

Sierra-Zamora, P. A., Bermúdez Tapia, M. A., \& Karán Benítez, C. A. (Eds.). (2020b). Las consecuencias del conflicto armado interno en el posacuerdo colombiano. Sello Editorial ESMIC.

Tovar Cabrera, G. A., \& Figueroa Pedreros, E. C. (2020). La Quinta Arma: Historia de la Aviación del Ejército de Colombia. Sello Editorial ESMIC.

Transparencia por Colombia. (2014). Índice de Transparencia de las Entidades Públicas, Resultados 2013-2014. https://indicedetransparencia.org.co/ITD/Contralorias

Unidad para la Atención y Reparación Integral de las Víctimas. (2019). Reportes. Red Nacional de Información. https://www.unidadvictimas.gov.co/es/reportes

Wright, E. (1995). El análisis de caso de la pobreza. En Julio Carabaña (Ed.), Desigualdad y clases sociales. Un seminario en torno a Erick O. Wright (pp. 133-150). Fundación Argentaria. 